Review

\title{
Ion Transport in Organic Electrolyte Solutions for Lithium-ion Batteries and Beyond
}

Argyrios V. Karatrantos ${ }^{1,2,}{ }^{*}$, Md Sharif Khan ${ }^{3,4}$, Chuanyu Yan ${ }^{1}$, Reiner Dieden ${ }^{1}$, Koki Urita ${ }^{5}$, Tomonori Ohba ${ }^{3}$, Qiong Cai ${ }^{2}$

1. Luxembourg Institute of Science and Technology, 5, avenue des Hauts-Fourneaux, L-4362 Esch sur-Alzette, Luxembourg; E-Mails: argyrioskaratrantos@gmail.com; chuanyu.yan@list.lu; reiner.dieden@list.lu

2. Department of Chemical and Process Engineering, Faculty of Engineering and Physical Sciences, University of Surrey, Guildford GU2 7XH, United Kingdom; E-Mail: q.cai@surrey.ac.uk

3. Graduate School of Science, Chiba University, 1-33 Yayoi, Inage, Chiba 263-8522, Japan; E-Mails: sharifkhanjnu@gmail.com; ohba@chiba-u.jp

4. CEA-Grenoble Center, LITEN,17 Rue des Martyrs, 38054 Grenoble, France

5. Graduate School of Engineering, Nagasaki University, 1-14 Bunkyo-machi, Nagasaki, 852-8521, Japan; E-Mail: urita@nagasaki-u.ac.jp

* Correspondence: Argyrios V. Karatrantos; E-Mail: argyrioskaratrantos@gmail.com

Academic Editor: Ahamed Irshad

Special Issue: Batteries: Past, Present and Future

Journal of Energy and Power Technology

2021, volume 3, issue 3

doi:10.21926/jept.2103043
Received: May 24, 2021

Accepted: September 09, 2021

Published: September 27, 2021

\section{Abstract}

The performance of metal-ion batteries at low temperatures and their fast charge/discharge rates are determined mainly by the electrolyte (ion) transport. Accurate transport properties must be evaluated for designing and/or optimization of lithium-ion and other metal-ion batteries. In this review, we report and discuss experimental and atomistic computational studies on ion transport, in particular, ion diffusion/dynamics, transference number, and ionic conductivity. Although a large number of studies focusing on lithium-ion transport in organic liquids have been performed, only a few experimental studies have been conducted in the

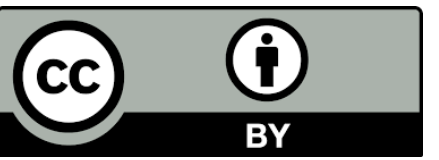

(C) 2021 by the author. This is an open access article distributed under the conditions of the Creative Commons by Attribution License, which permits unrestricted use, distribution, and reproduction in any medium or format, provided the original work is correctly cited. 
organic liquid electrolyte phase for other alkali metals that are used in batteries (such as sodium, potassium, magnesium, etc.). Atomistic computer simulations can play a primary role and predict ion transport in organic liquids. However, to date, atomistic force fields and models have not been explored and developed exhaustively to simulate such organic liquids in quantitative agreement to experimental measurements.

\section{Keywords}

Ion transport; diffusion; conductivity; organic electrolytes; transference number; nuclear magnetic resonance (NMR); molecular dynamics; multivalent ion solutions

\section{Introduction}

Electrochemical rechargeable batteries have received increasing attention as sustainable and environment-friendly energy storage devices and power sources. The performance of rechargeable metal- ion batteries depends on several parameters, such as the electrode material, energy density, charge/discharge rates [1], storage capacity and cycling stability, electrochemical stability window of the electrolyte $[2,3]$, ion mobility in the electrolyte $[4,5]$, etc. One method of increasing the energy density is by increasing the cation transference number in the electrolyte phase [6]. Fast charging also depends on ion transport and temperature. A key mechanism that influences fast charging is the ion transport: (i) through the electrodes, (ii) across the electrolyte/electrode interface for the anode and the cathode [7], and (iii) through the electrolyte phase, including solvation and desolvation of ions [1]. A low ionic conductivity of the electrolyte phase is a shortcoming that limits its performance and the use of metal-ion batteries in the industry. Such a low conductivity could be due to the low dissociation of ions in the solvents, low cation solvation, [8] or low ion migration (transference number) in the solvent. Although liquid organic (non-aqueous) electrolytes offer high conductivity $(1-10 \mathrm{mS} / \mathrm{cm})$ and well-dissociated ions for concentrations > 1 $\mathrm{M}$, they have a cation transference number below 0.5 , which implies that the total ionic conductivity results from the anion migration [6]. However, contradictory results have been reported regarding transference number measurements, concentrations, and temperature dependence by different methods [9-12]. Ion transport is based on ion solvation which is favored by aprotic solvents with a high dielectric constant $[13,14]$, ion dissociation which depends on temperature [15], ion motion through the solvent, long-range electrostatic interactions, and viscosity of the solvent. A direct relation exists between the motion of the ions and the ionic conductivity $[16,17]$. For instance, if the ions move faster, the ionic conductivity of the solution increases. A low value of the diffusion coefficient of ions can limit the charge/discharge rates and can lead to large concentration gradients across the anode, which will develop side reactions and eventually lead to cell failure.

Although extensive studies and reviews are available in the literature regarding the solvation structure of metal cations $\left(\mathrm{Li}^{+}, \mathrm{Na}^{+}, \mathrm{K}^{+}\right.$, etc.) $[18,19]$ and their desolvation [20] energies in several aprotic solvents, a comprehensive understanding (by using both experimental and computer simulation methods) of the ion transport mechanism in electrolyte solution is required to help optimize the ionic conductivity of rechargeable metal-ion batteries. To the best of our knowledge, the number of works on ion transport beyond lithium-ion batteries is rather limited. The higher 
natural abundance of alkali metals other than lithium (such as sodium [21-26] or potassium (K) [2729]) and their lower cost make them potential candidates for future energy storage devices. However, the lack of understanding of the ion transport mechanism can hinder their application.

In this review, we discuss the properties such as ion diffusion (self-diffusion and interdiffusion), dynamics, transference number, and ionic conductivity in the organic liquid (not polymer) electrolyte phases [30-35] ( not in the aqueous solutions, ionic liquids, polymer electrolytes, or electrolyte solutions in electrodes) for lithium-ion batteries (LIBS) and beyond, using both experimental and atomistic modeling methods. This review aims to provide fundamental insights into the current understanding of the effect of electrolyte transport on the battery design, its development, and its performance.

\section{Experimental Methods}

There are a few experimental methods and techniques that are used for evaluating the ion transport properties, such as the self-diffusion coefficient, the binary diffusion coefficients (interdiffusion), transference number of ions, and ionic conductivity of organic electrolyte solutions of batteries. The key points of these methods have been described very briefly below.

\subsection{PFG-NMR, DOSY, and E-NMR}

Pulsed-field gradient nuclear magnetic resonance (PFG-NMR) spectroscopy is an experimental technique that is used for detecting the self-diffusion coefficients of molecular species [36]. This NMR method overcomes the experimental limitations of the ordinary spin-echo method [37] when detecting small diffusion coefficients. Diffusion ordered spectroscopy (DOSY) is a two-dimensional representation of PFG-NMR [38], which has the advantage of separating multiple species with similar diffusion coefficients through their chemical shifts. Many building blocks can be used for constructing the PFG-NMR experiments $[39,40]$. For example, the spin-echo based PFG is the pioneer experiment [41] in which a stimulated echo enables a longer diffusion time (required for slow diffusing molecules) compared to the spin-echo [42], the double stimulated echo suppresses the convection artifacts [43], and a longitudinal eddy delay overcomes the echo distortion in the presence of eddy currents [44]. Although the pulse sequences for PFG-NMR experiments are getting large and complex, the principles remain unchanged: the pulsed-field gradients play two roles, namely, encoding and decoding the positional information of the NMR-active nuclei. During the encoding period, the nuclear spins located in the slices of the sample volume experience a gradient phase offset the magnetic field axis and are hence dephased. During the decoding period, the nuclear spins experience an opposite gradient phase offset, which effectively cancels out the dephasing and therefore reconstructs the signal, provided that these spins remain in the same slice. The displacement induced by self-diffusion leads to incomplete decoding of the position information and hence results in the attenuation of the signal. The degree of signal attenuation can be described by the following exponential relation [40]:

$$
I(g)=I_{0} * e^{-D \gamma^{2} \delta^{2} g^{2} \Delta^{\prime}}
$$

where $D$ is the diffusion coefficient, $\gamma$ is the gyromagnetic ratio of the nucleus, $\delta$ is the duration of the magnetic field gradient pulse, $g$ is the strength of the magnetic field gradient, and $\Delta^{\prime}$ is the 
effective diffusion duration, which depends on the duration, shape, and interval $(\Delta)$ of the gradient pulses, as well as the chosen pulse sequences [45]. The PFG-NMR spectra are collected with a set of incremental $g$, whereas the remaining parameters are kept fixed.

Although the self-diffusion of the ions and solvent molecules can be easily obtained from the PFG-NMR and DOSY experiments, electrophoretic NMR (E-NMR) is an indispensable technique for performing in situ measurements of ionic mobilities [46-51] under the influence of an electric field. E-NMR is an advanced version of PFG-NMR experiment, where an additional electric field is applied along the magnetic field. However, in contrast to PFG-NMR, the signal in E-NMR experiences a phase shift rather than attenuation. This contrast is due to the fact that the ensemble of nuclear spins belonging to the same ionic/molecular species experiences a coherent electrophoretic drift along the electric field in E-NMR, whereas the self-diffusion of these species in PFG-NMR is uncorrelated. The extent of phase shift is derived from the following exponential relations (Equations (2)-(4)) [51]:

$$
\begin{gathered}
I(E)=I_{0} * e^{-D \gamma^{2} g^{2} \delta^{2} \Delta^{\prime}} * e^{i \varphi(E)} \propto e^{i \varphi(E)} \\
\varphi(E)=\gamma \delta g \Delta_{E} E \mu
\end{gathered}
$$

where $\Delta_{E}$ is the duration of the electrophoretic drift, $E$ the strength of the electric field and $\mu$ is the electrophoretic mobility. The phase shift is calculated as $(\varphi(E)-\varphi(0))$, where $\varphi(0)$ is the phase of the NMR peak in the absence of the electric field. During an E-NMR experiment, the electric field intensity, $E$, is varied, whereas the PFG related parameters are fixed. As the electric field has a negligible effect on the uncharged species, their NMR signals experience practically no phase shift. Therefore, the signals of these uncharged species can also be used as an internal reference frame to compensate for the flow effect $[52,53]$.

The cation transference number in the dilute limit for a binary salt electrolyte, in which both ions are univalent ( $1: 1$ electrolyte) and assuming that the ions are completely dissociated, is given by the following equation $[6,54,55]$ :

$$
t_{+}=\frac{D_{+}}{D_{+}+D_{-}}
$$

where $D_{+}$and $D_{\text {- }}$ are the diffusion coefficients of the cations and anions, respectively. In this dilute limit, the transference number can be considered simply as the fraction of the total ionic conductivity that is carried by the cations [4].

However, in concentrated electrolyte electrolytic solutions [15], where ion association takes place, the diffusion coefficients predicted by the NMR contain contributions from not only the free ions, but also the ion pairs $[8,9]$ since the salt is not dissociated. Thus, the diffusion coefficients take the following form [9]:

$$
\begin{aligned}
& D_{+}^{N M R}=\alpha D_{+}+(1-\alpha) D_{\text {pair }} \\
& D_{-}^{N M R}=\alpha D_{-}+(1-\alpha) D_{\text {pair }}
\end{aligned}
$$

where $\alpha$ is the degree of dissociation and $D_{\text {pair }}$ is the diffusion coefficient of neutral ion pairs. The cation transference number (Equation 4), calculated using the diffusion coefficients of Equation (5) $\left(D_{+}^{N M R}, D_{-}^{N M R}\right)$ when the salts are not completely dissociated, will give erroneous results [9]. 
However, compared to the electrochemical methods, the NMR method has the advantage of not requiring a binary as a prerequisite.In addition, even multi-component mixtures can be investigated using the NMR method $[9,56]$.

\subsection{Method of Concentration Gradient}

This method involves the establishment and relaxation of a concentration gradient in a vertical cell. The concentration profile relaxes exponentially with time. In order to form a concentration gradient, two methods are followed: i) physically, by introducing a high-density solution at the bottom of the cell, having a less dense solution above it, or ii) by placing reversible electrodes on the top and bottom of the cell and applying voltage (Figure 1) [57]. Ions migrate due to the electric field created and thus form a concentration gradient. This gradient can be analyzed for short times using a galvanostatic polarization method (semi-infinite diffusion) [58] or for long times (restricted diffusion) [59].

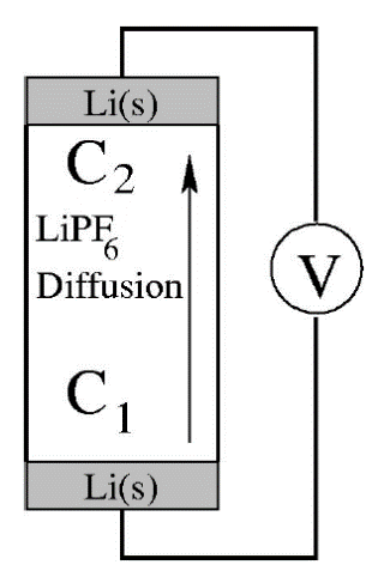

Figure 1 Schematic showing the principle of the diffusion coefficient determination. At the start of the experiment, $C_{1}=C_{2}$, and after applying a constant current for a predetermined time, $C_{1}>C_{2}$. Reprinted with permission from the article by Valøen [57]. Copyright 2005 Institute of Physics and IOP Publishing.

The salt diffusion coefficients can be calculated from the relaxation profiles obtained using the galvanostatic polarization experiments [60]. In particular, the galvanostatic method is comprised of three steps: (i) The cell is allowed to rest in the open circuit condition until equilibration, (ii) a small current is applied for a predetermined time, in which the concentration gradient is built, (iii) the current is switched off and the relaxation time of the open circuit potential is monitored [57]. However, the apparatus for such experiments should be isolated from vibrations [57].

The restricted diffusion was first developed by Harned and French [61]. It was later advanced by Newman and Chapman and was based on the long-time relaxation behavior, following an induced concentration gradient. In particular, Newman and Chapman used the refractive index in order to measure the concentration differences between two points of the vertical cell [62]. The binary diffusion coefficients calculated based on short or long time relaxation can be significantly different $[63,64]$. Other techniques that are used to monitor the relaxation of the concentration gradient or for measuring the transference number include the following: 


\subsubsection{Potentiostatic Steady-State Polarization}

Such experiments can be conducted using a two-electrode symmetrical lithium polarization cell (two Li metal electrolytes and an electrolyte phase) separated by a porous separator [59, 60]. After the potentiostatic steady-state polarization state is achieved, a linear concentration profile is established between the electrodes, and the short galvanic pulse polarization is designed such that the concentrations change only near the electrodes. The steady- state potentiostatic polarization experiment is based on the short-term relaxation behavior of the cell potential. After each individual polarization, an open- circuit voltage (OCV) phase of at least $3 \mathrm{~h}$ is applied to ensure complete relaxation of the concentration profile [64]. When a potential is applied, the measured current $\left(I_{0}\right)$ is a result of the migration of all charged species, which initially exists at uniform concentration throughout the cell. A constant current is obtained after the steady state $\left(I_{s s}\right)$ salt concentration profile is achieved, and the net anion flux is zero. The transference number is calculated as $t_{+}=I_{s s} / I_{0}$ [63], assuming that convection and instabilities at the Li electrodes can be neglected, the ions of the electrolyte are completely dissociated, and the applied polarization voltage is small [65]. However, in real cells, charge transfer and conduction through the dynamic passivation layer occur on the electrode. This layer affects the steady-state current by influencing the reactions that occur on the electrode [65].

Bruce and Vincent extended this method to electrolyte solutions with a variable ionic diffusion coefficient $[59,61,62]$, based on the dilute solution theory, which neglects the activity coefficients [66], [67] and is not applicable to concentrated electrolyte solutions [15, 62, 64, 68]. In such cases, the cation transference number, for small polarization potentials $(<10 \mathrm{mV})$, is given by the following equation [65]:

$$
t_{+}=\frac{I_{S S}\left(\Delta V-I_{0} R_{0}\right)}{I_{0}\left(\Delta V-I_{s S} R_{S S}\right)}
$$

where the subscripts 0 and ss indicate the initial and steady-state values, respectively, $R$ is the sum of the charge transfer resistance and the passivating film resistance, $\Delta V$ is the polarization voltage, and $I$ is the current. $R_{0}$ and $R_{s S}$ can be measured by recording the impedance spectra of the cell before the polarization, after the steady state has been reached, and the direct current (DC) bias potential has been removed [65].

For a fast estimation of the transference number, potentiostatic polarization is the best choice, but it has the disadvantage of being restricted in its applicability to binary electrolytes electrolyte solutions [7] and is not suitable for concentrated electrolyte solutions [63].

More discussion on other experimental methods for measuring the transference number based on polarization cell experiments can be found in references $[63,64]$.

\subsubsection{Galvanostatic Pulse Polarization}

The polarization time in a galvanostatic pulse experiment has no impact on the long-term relaxation behavior of the concentration gradient [64]. The concentration gradient (concentration changes only in the vicinity of the electrodes [64]) is not measured directly, but the cell potential difference during and after polarization determines the exact potential difference at the current interruption [9]. The polarization currents in galvanostatic experiments are selected such that the 
current density is below $0.3 \mathrm{~mA} / \mathrm{cm}^{2}$ since this guarantees the absence of lithium dendrite formation $[20,67]$. Subsequently to these galvanostatic pulse experiments, a steady state potentiostatic polarization is applied. The cation transference number is calculated by (i) measuring the cell potential after galvanostatic polarization (ii) the salt diffusion coefficient (by the restriction diffusion method), (iii) and the determination of the concentration dependence of the potential difference, using the following relation [58]:

$$
t_{+}=1-\frac{m F c_{\infty} \sqrt{\pi D}}{4\left(\frac{d \Phi}{d \ln c}\right)}
$$

where $c_{\infty}$ is the bulk concentration of the salt, $F$ is the Faraday constant, $D$ is the salt diffusion coefficient and $d \Phi / d l n c$ is the concentration dependence of the potential $\Phi$, and $m$ is the slope of a plot of the cell potential at the time of current interruption, which is obtained from $\Delta \Phi v s t_{i}^{1 / 2}$ fitting, where $j$ is the current density and $t_{i}$ is the polarization time [58]. The galvanostatic polarization method, for measuring the transference number, is more accurate for concentrated solutions, but it is time consuming since it combines three different measurements [9]. This method is restricted to binary electrolytes with the cation as the active species (anion flux is zero in the steady state), no convection, semi-infinite diffusion, and linear cell geometry. However, such a method can be applied to non-ideal, concentrated solutions $[9,68]$ and can be the most straightforward method to measure binary diffusion coefficients based on long-term relaxation behavior after galvanostatic polarization pulse [64].

It is worth noting that even for low salt concentration when the ion pairing is low, the transference number calculated by the galvanostatic polarization method results a lower value than the one calculated by the NMR method $[9,55]$.

\subsubsection{Ferrocene Cell Measurements}

Another method for measuring the transference number is based on experiments using a concentration cell and determining the thermodynamic factor, $\left(1+\frac{\partial \ln f_{ \pm}(c)}{\partial \ln c}\right)$, of binary solutions [62], where $f_{ \pm}$is the mean molar activity coefficient, which is the average of the mean molar activity coefficients of the cation and the anion, by measuring the lithium concentration dependent potential in a lithium electrode versus ferrocene/ferrocenium redox couple used as an internal standard $[63,69]$. The concentration dependence of the transference number, $t_{+}$, is usually not known a priori [11]. Alternatively, it can be assumed a constant transference number within a concentration range $(\delta c)$ about an average concentration, $c_{0}\left(\delta c<<c_{0}\right)$; thus, one can determine an average transference number within the differential concentration range $t_{+}\left(c_{0}+\delta c\right)$.

This method uses only the assumption that the transference method can be assumed to be constant within a differential concentration regime [59]. For a fast and accurate calculation of the transference number, this method is superior to the polarization cell experiments [63]. 
Concentration cells having liquids of different molalities $\left(m_{2}, m_{1}: m_{2}>m_{1}\right)$ of the monovalent electrolyte salt (e.g., LiX), have a potential difference, $E_{\text {trans, }}$ and the variation of the potential with concentration, $d E_{\text {trans, }}$ that are given by [9]:

$$
E_{\text {trans }}=-\frac{2 R T}{F} t_{-} \ln \left(\frac{m_{2} y_{2}}{m_{1} y_{1}}\right), d E_{\text {trans }}=-\frac{2 R T}{F} t_{-} d \ln \left(\frac{m_{2} y_{2}}{m_{1} y_{1}}\right)
$$

where $R$ is the ideal gas constant, $T$ is the temperature, and $y$ is the activity coefficient of the cations.

The potentials $E_{\text {trans }}$ and $E$ increase with the increasing concentration difference between the constant high concentration and the varied concentration of the salt.

If the activity coefficients are available, the transference number is determined by the electromotive force measurements.

If the activity coefficients are not available, a measurement of a cell without a liquid junction (with a salt bridge between the half cells with different concentrations) is necessary [9]. The potential is given by

$$
E=-\frac{2 R T}{F} \ln \left(\frac{m_{2} y_{2}}{m_{1} y_{1}}\right)
$$

The anion transference number is calculated using the following relation:

$$
t_{-}=\frac{d E_{\text {trans }}}{d E}
$$

The cation transference number for a binary electrolyte solution is $t_{+}=1-t_{-}$

This method assumes that the transference number is constant in the measured concentration regime and also requires an adequate organic (non-aqueous) salt bridge and reversible electrodes [9].

\subsubsection{UV/Vis Absorption}

The ultraviolet and visible (UV/Vis) absorption technique can be used for monitoring the relaxation of the concentration gradient [59] that has been introduced physically. In particular, it evaluates the change in concentration at a point that is at the one sixth distance of the liquid column height from the bottom of the column since by doing so, the selection errors on diffusion are reduced [62]. This technique can be useful for evaluating the diffusion coefficients in any liquid solution with a UV active species that have a diffusion coefficient, $D$, greater than $10^{-6} \mathrm{~cm}^{2} / \mathrm{s}[70]$. However, a limiting factor of this technique is the spatial resolution of the instrument.

\subsubsection{Moiré Pattern Method}

The Moiré pattern method is used for calculating the binary diffusion coefficient, $D_{ \pm}$, of salts in organic electrolyte solutions. This technique is based on the optical observation of the timedependent relaxation of the concentration profile after two electrolyte solutions with different concentrations are smoothly and instantly brought into contact in a diffusion cell [70, 71]. Thus, a stable interface is formed between the two electrolyte solutions, and mutual diffusion occurs [24]. 


\subsection{Rotating Disk Electrode Method}

In the rotating disk electrode (RDE) experiments, the idea is to measure the mass transfer of lithium in an organic electrolyte by finding the limiting current densities of lithium electrodeposition $\left(\mathrm{Li}^{+}+\mathrm{e}^{-} \Rightarrow \mathrm{Li}\right)$ on the RDE, which is suitable for finding the mass transport of salts in electrolytes [7274]. In the RDE experiments, for systems with limiting current density (presence of a plateau), the diffusion coefficient can be calculated using the following Levich equation $[65,66]$ :

$$
I=0.62 n F A D^{\frac{2}{3}} v^{-\frac{1}{6}} c \omega^{\frac{1}{2}}
$$

where $I$ is the disk electrode current, $n$ is the number of electrons transferred in the elementary reaction step, $F$ is the Faraday constant, $A$ is the disk electrode area $\left(\mathrm{cm}^{2}\right), D$ is the diffusion coefficient $\left(\mathrm{cm}^{2} / \mathrm{s}\right), v$ is the kinematic viscosity $\left(\mathrm{cm}^{2} / \mathrm{s}\right)$, and $\omega$ is the angular velocity of the disk electrode (rad/s). The diffusion coefficient is obtained from the slope of the / versus $\omega^{1 / 2}$ plot, which according to Equation (11), should be a straight line passing through the origin [43].

\subsection{Electrical AC Impedance Spectroscopy}

In order to measure the ionic conductivity of organic electrolyte solutions, the alternating current (AC) impedance technique can be applied. In particular, from the obtained Cole-Cole plots, the bulk resistance, $R_{\mathrm{b}}(\Omega)$, can be determined, and thus the conductivity, $\sigma$, can be calculated using the relation $\sigma(c, T)=t / R_{b} \cdot A[75,76]$, where $t$ is the thickness of the sample $(\mathrm{cm}), A$ is the area of the effective contact with the electrodes $\left(\mathrm{cm}^{2}\right), c$ is the concentration of the solution, and $T$ is the temperature. The ionic transference number can be measured by using the DC polarization method and is expressed by the relation $t_{i}=1-I_{e} / I_{t}$, where $I_{e}, I_{\mathrm{t}}$ are the electronic and total currents, respectively [75].

\section{Atomistic Computational Methods}

There are certain computational methods that are used to study ion transport (dynamics), diffusion, conductivity, such as the classical molecular dynamics (MD) and $a b$ initio molecular dynamics (AIMD) methods.

\subsection{Classical Molecular Dynamics}

Classical molecular dynamics (MD) involves the integration of the classic Newton equation, that governs the motion of particles, according to Equation 12 [10, 77-82]:

$$
m_{i} \frac{d \overrightarrow{v_{l}}}{d t}=F_{i}
$$

where $F_{i}$ is the force experienced by the particle $i, m_{i}$ is its mass, and $v_{i}$ is its velocity. This method can be used for predicting the structural as well as dynamical properties of atoms and molecules in the liquid state electrolytes. The dynamics (diffusion) of ions can be calculated from the mean square displacement (MSD) [83-86]: 


$$
D=\frac{1}{6 t} \lim _{t \rightarrow \infty}\left\langle\left|r_{i}(t)-r_{i}(0)\right|^{2}\right\rangle
$$

where $\left\langle\left|r_{i}(t)-r_{i}(0)\right|^{2}\right\rangle$ is the mean square displacement of the center of mass.

Using Equation (13), classical MD and $a b$ initio MD simulations can be employed for calculating the self-diffusion coefficients and the ion transport mechanism. The cation transference can also be obtained from the MD simulations using Equation (4). It is worth noting that the classical MD simulations allow for the modeling of longer trajectories and larger systems at less computational expense. $D$ can be used for calculating the diffusion activation energy by an Arrhenius type of relation $\left(E_{\mathrm{a}}\right.$, similar to the migration barrier obtained from the density functional theory (DFT) nudged elastic band (NEB) simulations) expressed by Equation (14) [87-89]:

$$
D=D_{0} \exp \left(-E_{a} / k T\right) \Leftrightarrow \ln D=\ln D_{0}-\frac{E_{a}}{k T}
$$

Here, $D_{0}$ is a temperature independent pre-exponential term, $T$ is the temperature, and $k$ is the Boltzmann constant. $E_{\mathrm{a}}$ is commonly obtained from the Arrhenius plots, i.e., from the gradient of $I n$ $D_{i}$ versus $1 / T$ plot. Finally, the ionic conduction of a species $i\left(\sigma_{i}\right)$ can be obtained through the NernstEinstein relationship by assuming that the motion of the ions is uncorrelated, and depends on selfdiffusion [77]:

$$
\sigma_{N E}=\frac{1}{6 t} \lim _{t \rightarrow \infty} \frac{e^{2}}{6 V K_{B} T} \sum_{i}^{n} z_{i}^{2}\left\langle\left|r_{i}(t)-r_{i}(0)\right|^{2}\right\rangle=\frac{e^{2}}{V K_{B} T}\left(\eta^{+} D_{+}-\eta^{-} \mathrm{D}_{-}\right)
$$

where $n=n^{+}+n^{-}$is the total number of mobile $i$ ions, and $q$ is the species charge. However, in a real solution, the motion of the anions and the cations is not uncorrelated, and the Nernst-Einstein relation provides an upper boundary prediction for the ionic conductivity with values always higher than the values determined by the electrochemical AC method.

Thus, we can calculate the ionic conductivity using the Einstein-Helfand method [77], by extracting it from the slope of the collective translational dipole moment, taking into account the cross correlations of the ions:

$$
\sigma=\frac{1}{6 t} \lim _{t \rightarrow \infty} \sum_{i}^{n}\left\langle\left|M_{j}(t)-M_{j}(0)\right|^{2}\right\rangle
$$

\subsection{Ab Initio Molecular Dynamics}

$A b$ initio molecular dynamics (AIMD) is one of the most precise methods for calculating the ionic diffusivity and conductivity [90,91]. Unlike MD simulations, interatomic interactions in AIMD simulations are implemented by establishing the Schrödinger equation using various approximation methods. These interatomic potentials have a significant advantage over the empirical potentials used in classical MD, in particular, when performing calculations for complex systems such as organic electrolytes. AIMD simulations can realistically explain the active chemical events accurately. For example, AIMD simulations can describe the bond breaking and association process by 
considering charge transfer and polarization effects during the simulations, which also allow the reproduction of the experimental conductivity of the ions in the electrolyte systems.

In the AIMD simulations, the accuracy of the interatomic potential depends closely on the level of the approximation methods used during the simulation for calculating the electronic structures of the systems. Recently, two major approximations have been considered widely, namely, the Born-Oppenheimer approximation, in which different treatments were used for the ions and electrons, and the Car-Parrinello approximation, in which the degrees of freedom of the ions and electrons are conjugated via fictitious dynamics variables [92]. Notably, the Car-Parrinello approximation requires less time for integrating the equation of motion compared to the BornOppenheimer approximation [93-95]. The major outcome of the AIMD simulations is the trajectories of the particles, from which the transport properties such as the diffusivity and conductivity can be inferred using the same equations as those detailed for the MD simulations. The primary shortcoming of an AIMD simulation lies in its critical computational cost relative to a classical MD simulation or indeed other $a b$ initio strategies such as NEB calculations. Therefore, organic electrolyte systems have rarely been investigated using AIMD simulations since organic electrolyte systems consist of a large number of atoms.

\section{Transport in Lithium- ion Batteries}

\subsection{Experiments}

The PFG-NMR technique has been widely used for measuring the diffusivity of ions and solvent molecules in lithium-ion battery electrolytes [16, 17, 31, 46-49, 96]. An experimental study was performed by Hayamizu [97] (Figure 2) to calculate the self-diffusion coefficient of $\mathrm{Li}^{+}, \mathrm{PF}_{6}{ }^{-}$, and various solvents, such as diethyl carbonate (DEC), propylene carbonate (PC), and ethylene carbonate (EC) for a range of temperatures [87]. From their study, it was concluded that the order of diffusivities was $D_{\text {solvent }}>D_{\text {anion }}>D_{\text {cation }}[15,87,98,99]$. The self-diffusion and activity coefficient of $\mathrm{Li}^{+}$ion depended greatly on the temperature [87]. The temperature dependence was correlated to the Volger-Fulcher-Tamman (VFT) fitting equation (Equation (14)). The $\mathrm{Li}^{+}$ion was observed to have a smaller diffusion coefficient compared to the $\mathrm{PF}_{6}{ }^{-}$anion, although it had a smaller size (van der Waals radii were 0.076 and $0.254 \mathrm{~nm}$, respectively [100]). This was due to the fact that $\mathrm{Li}^{+}$was solvated, and thus the hydrodynamic radius was larger than that of the anion [101]. It was noted that the Nernst-Einstein relation (Equation (15)) was corrected by incorporating a degree of dissociation $(\alpha)$. The value of $\alpha$ was observed to increase from 0.17 to 0.71 as the EC fraction increased from 0 to $100 \%$ [87, 88, 102]. For a $1 \mathrm{M}$ lithium bis(trifluoromethanesulfonyl)imide (LiTFSI): PC solution, the value of $\alpha$ was reported to be 0.6 [103]. 

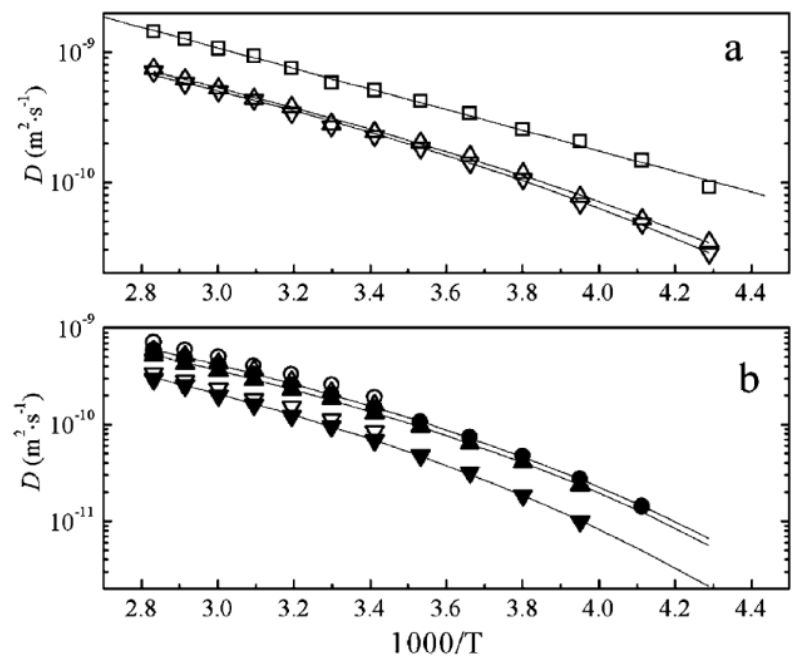

Figure 2 Arrhenius plots of $D_{\text {solvent, }} D_{\mathrm{PF} 6}$, and $D_{\mathrm{Li}}$ for: (a) diethyl carbonate (DEC) solution, squares (DEC), up triangles $\left(\mathrm{PF}_{6}^{-}\right)$, down triangles $\left(\mathrm{Li}^{+}\right)$and $(\mathrm{b})$ propylene carbonate $(\mathrm{PC})$ and ethylene carbonate (EC) single solvents, circles (EC or $\mathrm{PC})$, up triangles $\left(\mathrm{PF}_{6}{ }^{-}\right)$, down triangles $\left(\mathrm{Li}^{+}\right)$. Filled symbols correspond to PC solutions. The VFT fitting curves are shown. $D_{D E C}$ provides a linear fit [87]. Reprinted with permission from the article by Hayamizu. Copyright 2012 American Chemical Society.

Another experimental effort denoted that $\mathrm{Li}^{+}$ions were free from the strong interaction with anions $\mathrm{PF}_{6}{ }^{-}$anion were in a $\mathrm{PC}$ solution even at a high salt concentration (2-3 M) [104]. The $\mathrm{Li}^{+}$selfdiffusion coefficient exhibited a monotonically decreasing trend with increasing salt concentration [15, 104-108]. Furthermore, the self-diffusion coefficients of $\mathrm{Li}^{+}$and different spherical anions ( $\mathrm{PF}_{6}^{-}$, $\left.\mathrm{BF}_{4}^{-}\right)$in the $\mathrm{PC}$ solution were measured for different salt concentrations and were also found to decrease (Figure 3) [105]. The self-diffusion coefficient of the anion showed a slightly stronger concentration dependence than the one of the cation, for $\mathrm{LiPF}_{6}-\mathrm{PC}$ solutions. It was speculated that this behavior of concentration dependence was attributed to different solvation of cations and anions [9]. It is worth noting that the $\mathrm{LiBF}_{4}-\mathrm{PC}$ solution [109] exhibited higher diffusivity values than in the $\mathrm{LiPF}_{6}-\mathrm{PC}$ solution [65]. Thus, the higher conductivity that appeared in the $\mathrm{LiPF}_{6}-\mathrm{PC}$ solution could not be attributed to the higher ion diffusivities. The $\mathrm{Li}^{+}$ion forms weak ion pairs with $\mathrm{PF}_{6}{ }^{-}$, but strong ion pairs with $\mathrm{BF}_{4}^{-}$anion [99]. In addition, the cation $\left(\mathrm{Li}^{+}\right)$transference number of $\mathrm{LiBF}_{4}-\mathrm{PC}$ was observed to be higher for most salt concentrations. Thus, the ion association was weaker in $\mathrm{LiPF}_{6}-\mathrm{PC}$ solution than in the $\mathrm{LiBF}_{4}-\mathrm{PC}$ solution (Figure 3). The $\mathrm{Li}^{+}$transference number increased from 0.37 to 0.577 when the $\mathrm{LiPF}_{6}$ concentration decreased from 1.5 to $0.25 \mathrm{M}$ [65]. There were variations in the transference number values extracted by the direct electrochemical method and the PFG-NMR measurement $[9,35,65]$. The differences could be due to the different experimental conditions [65] or due to the fact that PFG-NMR does not take ion association into account $[55,110]$. 

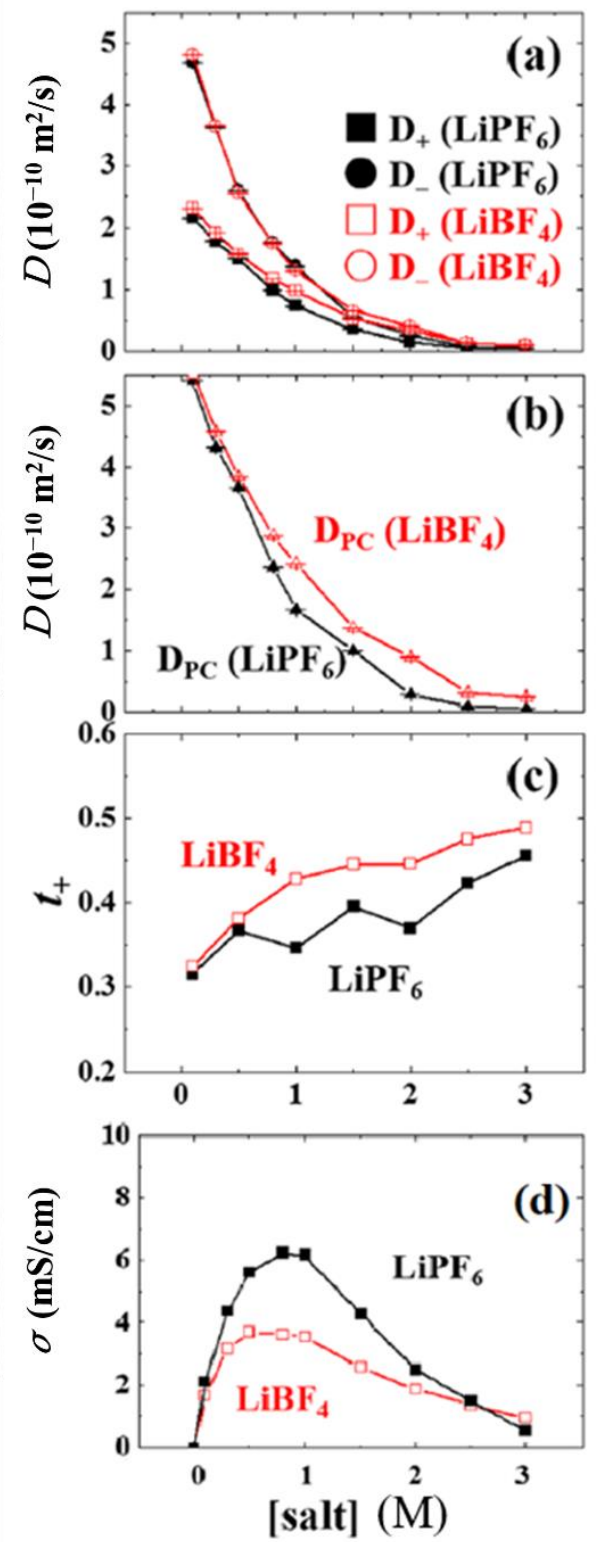

Figure 3 Self-diffusion coefficients of (a) $\mathrm{Li}^{+}$and anions, and (b) PC solvent measured by PFG-NMR as a function of salt concentration. (c) transference number of the $\mathrm{Li}^{+}\left(t_{+}\right)$and (d) ionic conductivities of $\mathrm{LiPF}_{6}-\mathrm{PC}$ and $\mathrm{LiPF}_{6}-\mathrm{PC}$ solutions [105]. Reprinted with permission from the article by Hwang. Copyright 2018 American Chemical Society.

In particular, the calculation of the transference number using the NMR method leads to an increasing cation transference number as a function of the salt concentration, whereas the calculation using electrochemical methods (such as galvanostatic polarization), which detect only "free" ions, results in a decreasing cation transference number as a function of the salt concentration, a result that is in agreement with the electrostatic theories [111, 112].

Notably, the $\mathrm{Li}^{+}$transference number was found to be almost constant (slight variations) as a function of the salt concentration (and temperature) in a mixture of PC: EC: dimethyl carbonate (DMC) solvents [57]. However, the binary diffusion coefficient was found to greatly depend not only on the temperature, but also on the salt concentration $[57,64,69,113]$. This was also confirmed by 
the Moiré pattern method in various PC solutions containing salts such as $\mathrm{LiClO}_{4}[70]$, $\mathrm{LiPF}_{6}, \mathrm{LiBF}_{4}$, and LiTFSI [71].

The $\mathrm{Li}^{+}$transference number in an EC:ethyl methyl carbonate (EMC) mixture, at $298 \mathrm{~K}$, was observed to decrease with increasing $\mathrm{LiPF}_{6}$ salt concentration, reaching a maximum of 0.37 at a salt concentration of $0.2 \mathrm{M}[60]$. In such solutions, the dependence of the ionic conductivity with the $\mathrm{LiPF}_{6}$ concentration, $c$, could be fitted by a polynomial of the form $\sigma=A_{1} C^{3}+A_{2} C^{1.5}+A_{3} C[60,114]$. In another study of EC:EMC solutions with different salts, such as $\mathrm{LiPF}_{6}, \mathrm{LiBF}_{4}$, and $\mathrm{LiN}\left(\mathrm{SO}_{2} \mathrm{C}_{2} \mathrm{~F}_{5}\right)_{2}$, diffusion was investigated using the PFG-NMR method [115]. According to Capiglia et al. [115], the cation transference number ranged between $0.37-0.49$, and the maximum value of 0.49 was obtained for $0.5 \mathrm{M}$ solution of $\mathrm{LiBF}_{4}$ in the EC:EMC (2:8) solution. The $\mathrm{PF}_{6}{ }^{-}$transference number was found to be higher than the one of $t_{\mathrm{Li}}{ }^{+}, t_{\mathrm{PF} 6}{ }^{-}>t_{\mathrm{Li}}[115]$. The $\mathrm{Li}^{+}$transference number was reported to be 0.34 in $\gamma$-Butyrolactone (GBL), independent of the LiPF 6 concentration from 0.1-0.8 M [116]. The error in the experimentally measured $\mathrm{Li}^{+}$transference numbers (using the PFG-NMR method) was estimated to be $5 \%$ and $20 \%$ in binary and ternary solutions, respectively [117]. In addition, organic solutions of lithium bis(fluorosulfonyl)imide (LiFSI) in DMC, EC, or mixtures of them $[55,118]$ were also investigated at $298 \mathrm{~K}$ using the PFG-NMR method [119]. As in the previous studies, $\mathrm{Li}^{+}$ion diffusion was observed to be the lowest (one order of magnitude lower than bis(fluorosulfonyl)imide(FSI)), despite having the smallest size, due to its strong coordination with the solvent molecules [119]. The diffusivity of ions in DMC was three times higher than those in EC [119]. Furthermore, the transport properties (self-diffusion coefficient and ionic conductivity) of $\mathrm{LiPF}_{6}$ and tris(pentafluoroethane)-trifluorophosphate (LiFAP) were measured in an EC:DMC mixture (50:50 w:w) [120]. The self-diffusion coefficient of $\mathrm{Li}^{+}$ion was very similar for both electrolytes and close to FAP- anions. However, it was 1.6 times smaller than that of the $\mathrm{PF}_{6}{ }^{-}$anions [120]. Following the Nernst-Einstein relation (Equation 15), a higher degree of dissociation was observed for LiFAP [121] compared to that for $\mathrm{LiPF}_{6}$ or lithium 4,5-dicyano-2-(trifluoromethyl)imidazole (LiTDI) [110] in an EC:DMC mixture, due to the higher delocalization of the negative charge in the AAP $^{-}$anion [120]. The ion dissociation was observed to decrease with decreasing temperature and the neutral ion aggregates formed in the electrolyte solution affected the cation transference number $[8,19,121$, 122].

Furthermore, numerous experiments were performed on the EC:DMC (1:1 w:w), EC:EMC (3:7 $w: w)$, and EC-free electrolyte (EMC:FEC (19:1 w:w)) solutions for measuring their ionic conductivities, binary diffusion coefficients, $D_{ \pm}$, transference numbers in the temperature range of $-10^{\circ} \mathrm{C}$ - to $\left.50{ }^{\circ} \mathrm{C}\right)$, and concentration range of LiPF 6 (0.1 M-3.0 M), as can be seen in Figure 4 [69]. In particular, they used a novel analysis for the determination of transference numbers based on the analysis of concentration cell potentials and the short-term potential relaxation after galvanostatic pulses in the symmetric lithium coin cells $[63,64,69]$. There was a qualitative agreement of the data by Landensfiend [69] with the data by Nyman et al. [60], however the strong decrease in the $\mathrm{Li}^{+}$ transference number observed with increasing LiPF 6 concentration and decreasing temperature [69] was observed, in contrast to the data by Valoen and Reimers (measured $t_{+} \approx 0.3-0.4$, though they mentioned the difficulty in achieving a precise result) [57], who assumed temperature- and concentration-independent transference number. Further, the binary diffusion coefficient, $D_{ \pm}$, of $\mathrm{LiPF}_{6}$-acetonitrile $(A C N)$ and $\operatorname{LiPF}_{6}-\mathrm{EC}: \mathrm{DEC}(1: 1 \mathrm{w}: \mathrm{w})$ [12] solutions followed the relations $D=$ $3.018 \times 10^{-5} \exp (-0.357 c)$ and $D=2.582 \times 10^{-5} \exp (-2.856 c)$, respectively, as they were estimated by UV/Vis absorption [58]. For 0.1 to $1.5 \mathrm{M} \mathrm{LiPF}_{6}-\mathrm{EC}$ : DEC (1:1 w:w) solutions, using the concentrated 
solution theory $[123,124]$ and the Darken relation [125] along with the PFG-NMR measurements, the degree of dissociation, $\alpha$, was measured to be in the range from 0.61 to 0.37 [15].
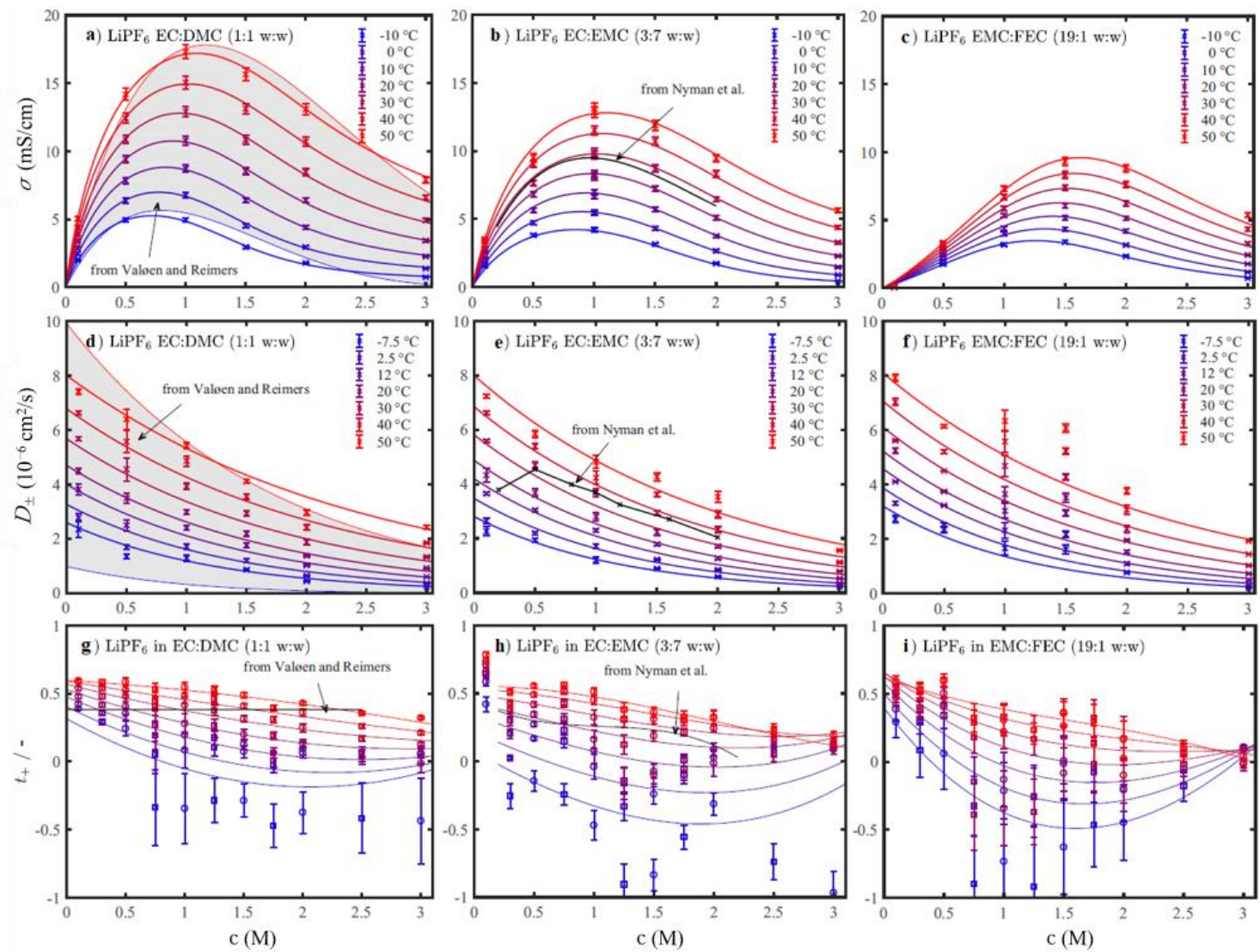

Figure 4 (a), (b), (c) lonic conductivity, $\sigma$; (d), (e), (f) binary diffusion coefficient, $D$; and (g), (h), (i) transference number, $t_{+}$, between $-10{ }^{\circ} \mathrm{C}$ and $50{ }^{\circ} \mathrm{C}$ of 0.1-3.0 M LiPF 6 in EC:DMC (1:1 w: w), EC:EMC (3:7 w:w), and EMC:FEC (19:1 w:w) solvents, respectively. Reprinted with permission from the article by Landesfeind et al. [69].Copyright 2019 Institute Physics and IOP Publishing.

It was hypothesized that these changes in the ionic conductivity as a function of the salt concentration [126] were caused by the structural changes that switched the conductivity mechanism from vehicular to a Grotthuss-type (ion hopping) or a mixture of both mechanisms [127]. The origin of the concentration exhibiting the highest conductivity, $C_{\max }$, was correlated to the eutectic composition in the salt-solvent phase diagram [127].

Furthermore, the self-diffusion coefficient of $\mathrm{Li}^{+}$with different anions $\left(\mathrm{PF}_{6}^{-}, \mathrm{ClO}_{4}{ }^{-}\right)$, in $\mathrm{PC}, \mathrm{EC}$ : DEC, and EC:DMC solutions was estimated from the current density data according to the Levich equation [128]. The diffusion coefficient was observed to increase in the order $\mathrm{LiClO}_{4}-\mathrm{PC}<\mathrm{LiPF}_{6}-\mathrm{EC}: \mathrm{DEC}<$ $\mathrm{LiPF}_{6}-\mathrm{EC}: \mathrm{DMC}$ with the salt concentration, with a maximum value of $1.39 \times 10^{-5} \mathrm{~cm}^{2} / \mathrm{s}$ for $1 \mathrm{M} \mathrm{LiPF}_{6}$ EC:DMC (1:1) solution [128].

In addition, the diffusion coefficients of 14 pure organic solvents, such as EC, tetrahydrofuran (THF), $\gamma$-Butyrolactone (GBL) [116] appeared to exhibit a good correlation with viscosity, according to the Stokes-Einstein relation [84, 129]: 


$$
D=\frac{k_{B} T}{6 \pi \eta r_{s}}
$$

where $D$ is the diffusion coefficient, $k_{B}$ is the Boltzmann constant, $T$ is the absolute temperature, $\eta$ is the viscosity, and $r_{s}$ is the Stokes radius (Figure $5 a$ ). The Stokes-Einstein relation shows that the diffusion coefficient in a liquid is inverse proportional to the viscosity of the liquid. Thus, the diffusion coefficient decreases with the salt concentration since the viscosity of the electrolyte phase increases [101].
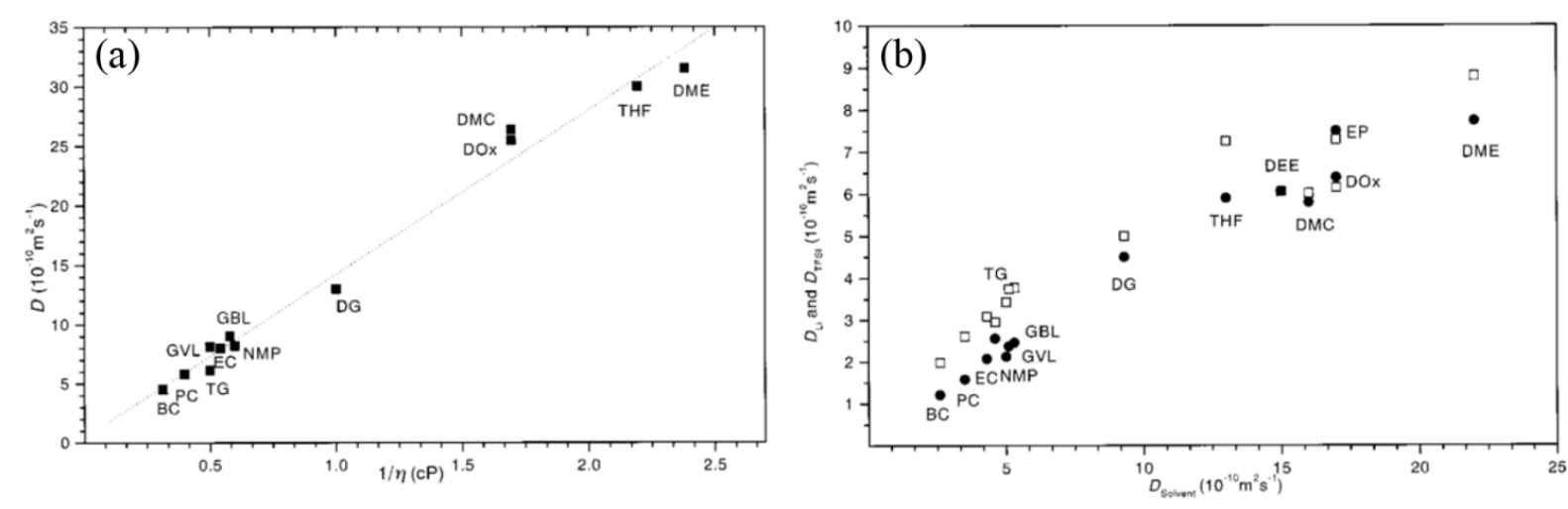

Figure 5 (a) Correlation between the diffusion coefficients determined from the pulsed gradient spin-echo NMR (PGSE-NMR) at $30{ }^{\circ} \mathrm{C}$ and the viscosity at $25{ }^{\circ} \mathrm{C}$, which is reported in the literature for pure liquids. (b) Diffusion coefficients of $\mathrm{Li}$ and TFSI ions against those of the pure solvents. The solid circles and open squares indicate the diffusion coefficients of the Li and TFSI ions, respectively. Note: the viscosity data of EC was obtained at $40^{\circ} \mathrm{C}$. [BC: Butylene carbonate, DG: Diglyme, DMC: Dimethyl carbonate, DME: 1,2,-dimethoxyethane, DOx: 1,3-dioxolane, EC: Ethylene carbonate, GBL: $\gamma$ butyrolactone, GVL: $\gamma$-butyrolactone, PC: Propylene carbonate, NMP: N-methyl-2pyrrolidinone, TG: Triglyme, THF: Tetrahydrofuran] [31]. Reprinted with permission from the article by Hayamizu et al. Copyright 1999 American Chemical Society.

The relationship between the diffusion of the electrolyte ions $\left(\mathrm{Li}^{+}\right.$and $\left.\mathrm{TFSI}^{-}\right)$in various solvents and pure solvents shows good linearity; the diffusion coefficient of solvents governs to electrolyte ions diffusion (Figure 5b). From the comparison of the diffusion coefficients, it can be seen that the TFSI $^{-}$anion diffuses faster than the $\mathrm{Li}^{+}$cation, although the size of a bare $\mathrm{Li}^{+}$ion is smaller than that of a $\mathrm{TFSI}^{-}$ion. This is because the $\mathrm{Li}^{+}$ions are solvated by the organic solvents with the average solvation shell containing two solvent molecules, whereas the TFSI ${ }^{-}$anions are not solvated [31]. The solvents can be classified into three categories depending on the correlation of the $\mathrm{Li}^{+}$and TFSI ${ }^{-}$ diffusion coefficients and the ionic conductivity. One category is the cyclic carbonates and esters, which have a direct correlation to the ionic conductivity and the diffusion coefficients of lithium and TFSI. The second category is triglyme (TG), diglyme (DG), dimethoxyethane (DME), which are the glyme family $\left(\mathrm{CH}_{3} \mathrm{O}-\left(\mathrm{CH}_{2} \mathrm{CH}_{2} \mathrm{O}\right)_{m}-\mathrm{CH}_{3}\right)$, in which as $m$ increases, the ionic conductivity and the diffusion coefficient increase. The third solvent category includes dimethyl carbonate (DMC), diethoxyethane (DEE), ethylene propionate (EP), and dioxolane (DOx), in which the ionic conductivity is small due to a stable ion-pair formation $[8,31]$. 


\subsection{Simulations}

In this section, we will focus on the atomistic modeling studies of electrolytes for LIBs. Several computer simulation studies are available in the literature [77, 98, 99, 106, 107, 130-139] that focus on diffusion in such organic liquid solutions. In particular, the DFT calculations and AIMD simulations have been used for simulating the diffusion of $\mathrm{Li}^{+}$within the liquid EC solvent [140]. Although the work of Pham et al. [133] claimed to be able to simulate the diffusion behavior of $\mathrm{Li}^{+}$in the EC solvent, the short-scale dynamics [141] of $\mathrm{Li}^{+}$ion, up to $10 \mathrm{ps}$, was actually simulated. In particular in that study [133], the diffusion coefficient of $\mathrm{Li}^{+}$was calculated to be $4.3 \mathrm{~cm}^{2} / \mu$ s in a $0.23 \mathrm{M} \mathrm{LiPF}_{6}$ concentration in the EC solvent, which was in a different scale compared to the experimental values of Hayamizu [87]. In another study implementing the $a b$ initio and classical MD simulations, a good agreement between the simulated $\mathrm{Li}^{+}$diffusion was achieved in comparison to the experiments at $300 \mathrm{~K}$ [87], a single $\mathrm{Li}^{+}, \mathrm{PF}_{6}^{-}$pair in $249 \mathrm{PC}$ molecules were simulated in this study [142]. This corresponded to a $0.05 \mathrm{M} \mathrm{PC}$ solution, whereas the experimental measurements [87] referred to a $1 \mathrm{M} \mathrm{PC}$ solution [87]. Furthermore, in another study of ab initio molecular dynamics [143], the $\mathrm{Li}^{+}$ ion dynamics was measured in a liquid EC solvent at a high temperature (450 K). $\mathrm{Li}^{+}$ion solvation and diffusion in PC [100], EC, EMC solvents or mixtures of them [122, 144] were calculated from the $a b$ initio [100] and classical reactive MD simulations [141]. In particular, a higher $\mathrm{Li}^{+}$diffusion was observed in a linear carbonate solvent (EMC) compared to that in a cyclic carbonate solvent (PC [100] or EC[141]).

Only recently, the self-diffusion of $\mathrm{Li}^{+}$for different electrolyte concentrations was calculated in the range of 298-303 K, using the classical MD simulations, in PC solutions [99, 107, 136, 145], EC solutions [130, 131, 136-139, 146], DME solutions [132], DMC solutions [137, 139, 147, 148] or even mixtures of them, such as EC:DMC [137, 145, 146], PC:DME [145] or ternary (EMC:DMC:EC) mixtures [149]. At low $\mathrm{LiPF}_{6}$ concentration (0.1 M), the EMC-LiPF 6 electrolyte was observed to exhibit higher ion dynamics than the DEC-LiPF 6 and DMC-LiPF 6 electrolytes (DMC-LiPF 6 electrolyte exhibited the lowest) [147]. A polarizable force field for the LiTFSI-DME electrolyte quantitatively predicted the $\mathrm{Li}^{+}, \mathrm{TFSI}^{-}$, and DME diffusivities, for 0.5-1 M concentration, which were compared to the experimental values [132]. The $\mathrm{Li}^{+}$transference number was found to be 0.47-0.49 depending on the salt concentration [132]. The ionic conductivity of that solution increased up to $1 \mathrm{M}$ concentration and then decreased [132]. A similar result for the behavior of the ionic conductivity, as a function of the salt concentration, was observed for the EC-LiPF 6 solutions [131], using a nonpolarizable force field $[134,150]$. The diffusivity of both ions was found to decrease with the salt concentration following an Arrhenius type of relation [131].

In another study, it was found that in PC solutions, there are contact ion pairs and multi ion complexes formed at high concentrations, which impact the transport properties (diffusivity and ionic conductivity) [136]. However, it is well-known from several studies that non-polarizable force fields do not reproduce ion transport accurately. In particular, they underpredict the dynamic (diffusive) properties since they overestimate the ion-ion correlations [151]. Several atomistic computational studies with non-polarizable force fields have failed to predict ion transport (diffusion) in organic liquid electrolyte solutions (PC [99, 134, 136] and EC [131, 134, 137, 147, 150]).

Furthermore, the self-diffusion coefficient and ionic conductivity predictions using a polarizable force field for the LiPF 6 -EC:DMC electrolyte solution [146] were found to be in good agreement with the experimental measurements $[31,152,153]$. The simulated degree of ion dissociation was 
overestimated compared to the experimental values [127]. A monotonic increase in the degree of dissociation and the ion and solvent diffusion coefficients was observed on increasing the EC content of the solvent mixture [127]. An almost perfect agreement of the ionic conductivity dependence on the salt concentration, between a polarizable force field for the LiTFSI-PC and LiTFSIDME solutions [154] and the corresponding experimental values [155] was observed, as can be seen from Figure 6.

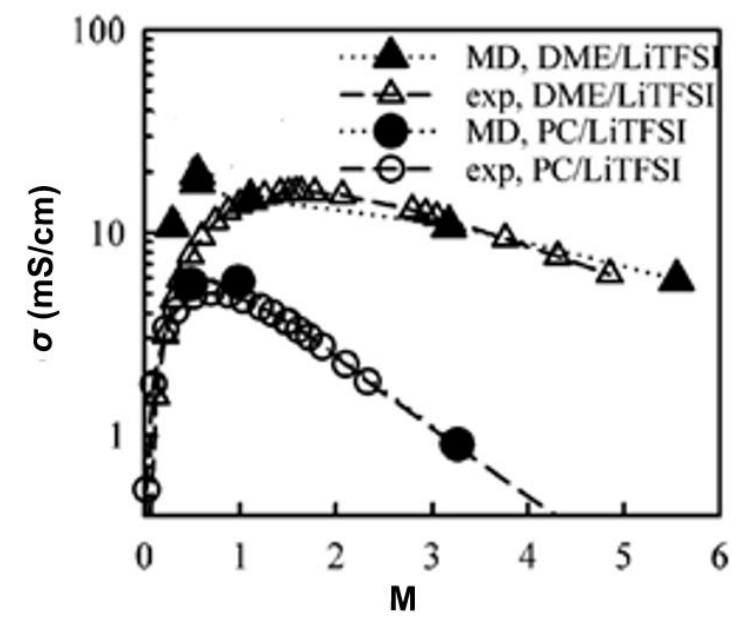

Figure 6 Conductivity of the DME/LiTFSI electrolyte solution at $308 \mathrm{~K}$ and the PC/LiTFSI electrolyte solution at $298 \mathrm{~K}$ obtained from experiments and MD simulations [154]. Copyright 2006 American Chemical Society.

Karatrantos et al. [77] modeled PC solutions with a $1 \mathrm{M} \mathrm{LiPF}_{6}$ concentration and calculated the ion and solvent diffusion over a broad temperature range (353-253 K), and compared them with the experimentally measured values [87]. The solvent molecules and atoms were represented by an atomistic model, and the charges of the solvent and the ions were scaled [77]. Not only the PC diffusivities but also the calculated ions diffusivities were found to be in accordance with the experimental measurements performed by Hayamizu [87] over a range of temperatures (353-293 K) (Figure 7). It was shown that $D_{\mathrm{PC}}>D_{\mathrm{PF} 6}{ }^{-}>D_{\mathrm{Li}}{ }^{+}$following the experimental trend. By appropriate charge scaling, both the generalized amber force field (GAFF) and the optimized potential for liquid simulations all atom (OPLS-AA) force field could predict the ion and PC diffusivities for a range of temperatures. To the best of our knowledge, there have been no studies, even with polarizable force fields [108], that can predict the ion diffusion and PC diffusion that are so in- line with the experimental measurements. 

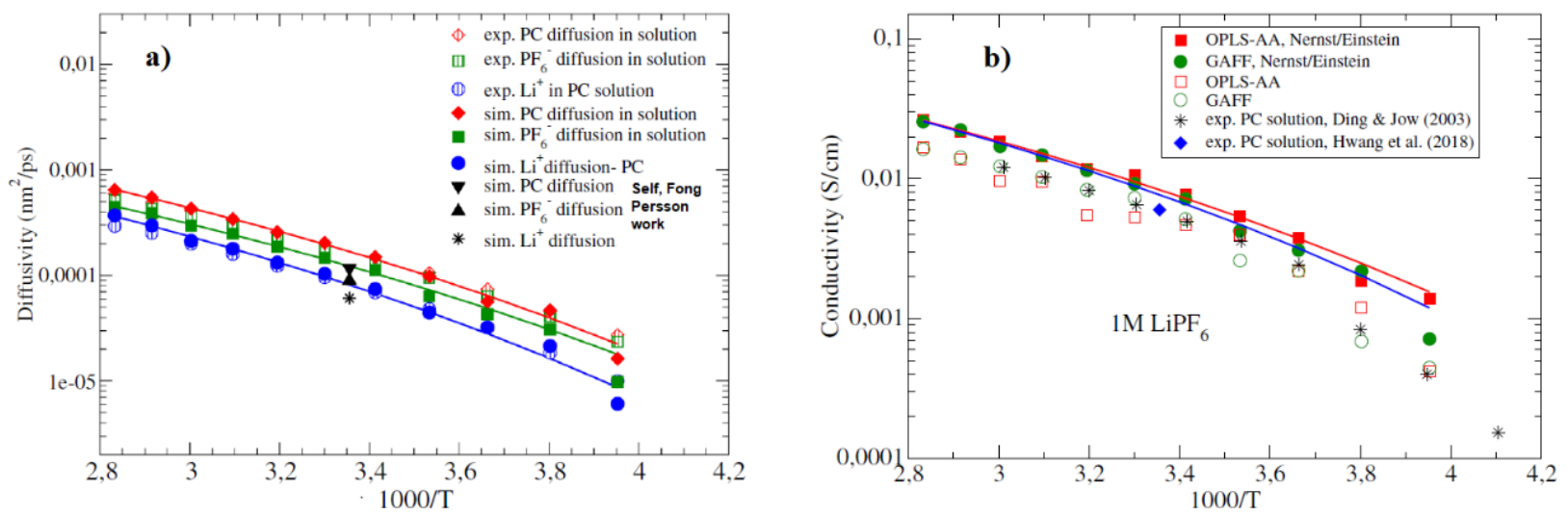

Figure 7 (a) Self-diffusion of PC solvent (diamonds), $\mathrm{PF}_{6}{ }^{-}$anion (squares), and $\mathrm{Li}^{+}$cation (circles), at different temperatures using the GAFF with the PC solvent charges scaled by $90 \%$ and electrolyte ions by $85 \%$. Open symbols are experiments by Hayamizu [87]. Lines are the fits of the VFT equation (Equation (14)) to the simulation data. Star, up and down triangles are $\mathrm{Li}^{+}, \mathrm{PF}_{6}, \mathrm{PC}$ the simulated diffusivities by Self et al. [107]. (b) Conductivity of $1 \mathrm{M} \mathrm{LiPF}_{6}-\mathrm{PC}$ solutions at different temperatures as predicted with two forcefields, (circles): GAFF with the PC solvent scaled by $90 \%$ and ions by $85 \%$, (squares) : OPLS-AA with the PC solvent scaled by $80 \%$ and ions by $90 \%$. Filled symbols are the predictions of Nernst-Einstein relation. Lines are the fitting to the simulation data of Nernst-Einstein relation (Equation (15)). Open symbols denote the static ionic conductivity measurements (Equation (16)) from the simulations data. Filled diamond symbol is the experimental value of the same $1 \mathrm{M} \mathrm{LiPF}_{6}-\mathrm{PC}$ solution [105]. Star symbols are the experimental values of $1 \mathrm{M} \mathrm{LiPF}_{6}-\mathrm{PC}$ solution [76]. Reprinted with permission from the article by Karatrantos et al. Copyright 2020 Elsevier B. V.

In addition, the ionic conductivity of $1 \mathrm{M} \mathrm{LiPF}_{6}-\mathrm{PC}$ solution at different temperatures was predicted using the two force fields (GAFF: with the PC solvent charges scaled by $90 \%$ and electrolyte ions by $85 \%$ and OPLS-AA : with the PC solvent charges scaled by $80 \%$ and electrolyte ions by $90 \%$ ) and compared with the corresponding values obtained using the Nernst-Einstein relation (Figure 7b) (Equation (15)). The results were found to be in accordance with the experimental measurements by Hwang et al. [105] and Ding and Jow [76].

Furthermore, it was found that the DMC solution exhibited a higher diffusivity than EC (or EC:DMC mixtures) solutions and exhibited lower conductivity (contrary to the Nernst Einstein theory) [137]. This was because the clusters observed in the DMC solution had zero net charge, whereas the clusters in EC (or EC: DMC mixture) had a net charge of +1 (or -1 ) , and thus they were conductive. Such differences in the clustering behavior could be explained by the different dielectric constants of EC and DMC [137]. In ternary (EMC:DMC:EC) solutions, owing to the higher viscosity of a cyclic (EC) co-solvent, the solvent viscosity was increased. Thus, the diffusional motion of ions became slower with increasing EC fraction [137]. Similar behavior was observed for the PC:DME and EC:DMC mixtures [145]. The viscosity of the electrolyte solution and the solvation structure were changed by the EC co-solvent, contributing to the ionic conductivity in the opposite manner, meaning that the ionic conductivity was optimized at a certain amount of EC [137]. In mixtures of cyclic (EC) and linear (DMC) solvents, the exchange dynamics of the solvents depended on the mixture ratio. The rotational dynamics of the linear (but not of cyclic) solvent was found to be sensitive to the mixture 
ratio [130]. Density variations of the electrolyte solutions could also alter the ion mobility and the $\mathrm{Li}^{+}$solvation structure $[106,139]$. A comparison of the effect of the type of anions (spherical or linear anions) on the ionic conductivity was investigated for the $\mathrm{LiBF}_{4}$ and LiTFSI salts in adiponitrile (ADN) solvent [156]. The higher affinity of the $\mathrm{BF}_{4}^{-}$with $\mathrm{Li}^{+}$compared to that of $\mathrm{TFSI}^{-}$linear anion with $\mathrm{Li}^{+}$ implied that the ionic conductivity decreased remarkably at various concentrations [156]. However, in all of the above studies, the diffusion coefficients, as predicted by the original non-polarizable GAFF $[157,158]$ and OPLS-AA $[134,159]$ force fields, were underestimated in comparison to the experimentally measured values.

It has been observed from simulations $[107,135,136]$ as well as experiments $[99,104]$ that the increase in the salt concentration beyond $1 \mathrm{M}$ translates into a decrease in diffusion, as can be seen from Figure 8. In particular, the diffusion mechanism of $\mathrm{Li}^{+}$at room temperature was observed to be a mix of vehicular and structural diffusion in the 1-3 $\mathrm{M}$ concentration range (Figure 8), exhibiting an increase in the structural diffusive mode in the super-concentrated regime $[57,107,127,138]$. In addition, a polarizable force field was used for modeling the LiTFSI salts in the EC solutions [138], and the prediction of ions and EC diffusivities by MD were in fair agreement (self-diffusion coefficients predicted by MD were $30 \%$ higher than those obtained from experimental measurements) with the experimental values [31]. Similarly, the ionic conductivity measured from the MD simulations was found to be $30 \%$ higher than the experimental values. The degree of uncorrelated ion motion and the fraction of free ions decreased slightly with the temperature increase, indicating increased ion clustering with temperature increase [138]. Furthermore, ion aggregates $[137,146]$ contributed approximately $50 \%$ to the overall charge transport with another $50 \%$ contribution from the diffusion of free ions [138]. In a similar study, but with the COMPASS II force field, the $\mathrm{Li}^{+}$ionic conductivity and diffusion were measured for various salt concentrations in the PC solvent [135] at room temperature and were found to be in quantitative agreement with the experimental data at $298 \mathrm{~K}$. 


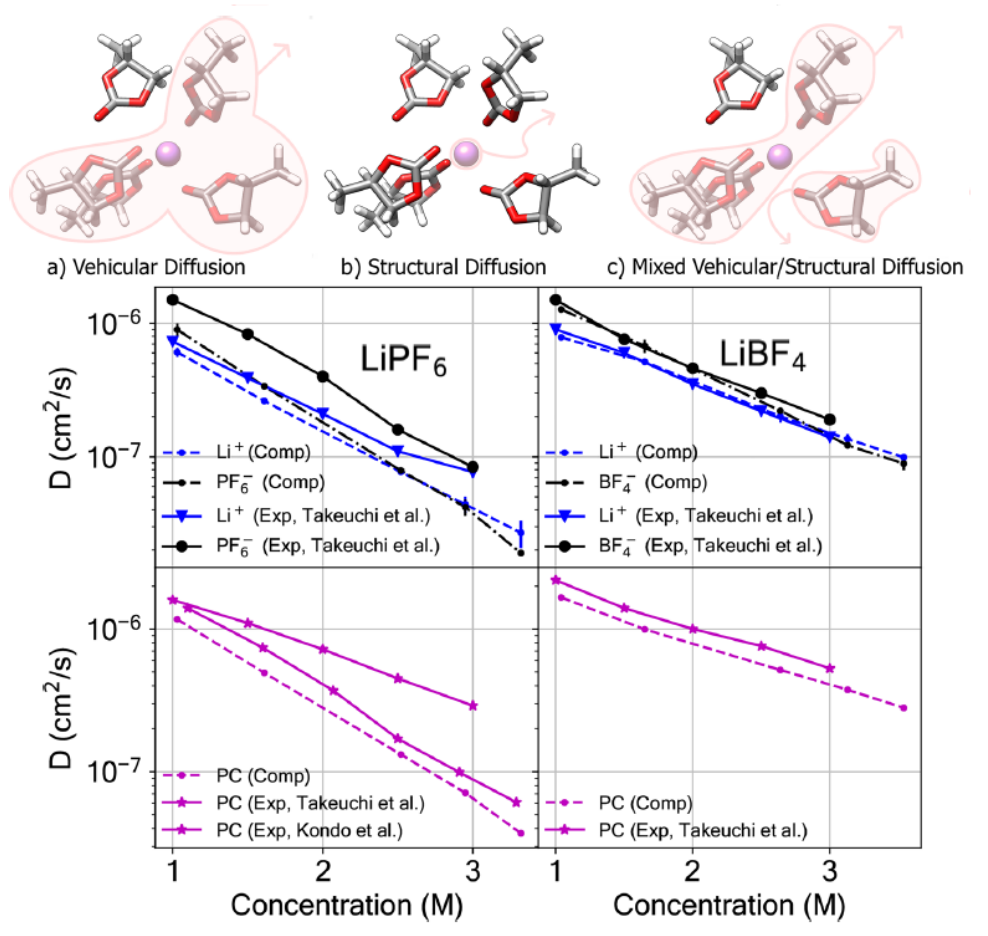

Figure 8 Illustration of diffusion mechanisms, (a) vehicular diffusion, (b) structural diffusion, and c) mixed structural and vehicular diffusion. $\mathrm{O}, \mathrm{C}, \mathrm{H}$, and $\mathrm{Li}$ atoms are shown as red, gray, white, and purple, respectively. Bottom panel: Diffusion constants as a function of salt concentration for ions $\left(\mathrm{Li}^{+}, \mathrm{PF}_{6}{ }^{-}, \mathrm{BF}_{4}{ }^{-}\right)$and $\mathrm{PC}$ in $\mathrm{PC}$ electrolyte solutions. Experimental values are taken from the literature $[99,104]$. Error bars, when smaller than the symbols for computed data are not shown [107]. Reprinted with permission from the article by Self et al. Copyright 2019 American Chemical Society.

Furthermore, classical MD simulations of $\mathrm{LiTFSI}$ and $\mathrm{LiNO}_{3}$ electrolytes in mixtures of 1,2dimethoxyethane (DME) and 1,3-dioxolane (DOL) solvents for Lithium-Sulfur batteries [160] showed a strong dependence of the $\mathrm{Li}^{+}$self-diffusion with temperature. In addition, the diffusion mechanism of $\mathrm{Li}_{2} \mathrm{~S}_{4}$ in DOL was of the mixed vehicular type and hopping character $[160,161]$.

\section{Transport in Na-/K- ion Batteries}

\subsection{Experiments}

Although there are a plethora of works investigating the structure and solvation of $\mathrm{Na}^{+}$and $\mathrm{K}^{+}$ ions [20, 118, 162-165], specifically in the aprotic solvents used in Na-ion batteries (NIBS) [3] and Kion batteries (KIBs) [166, 167], only a few experimental efforts [168, 169] and even fewer computer simulation studies have been done that investigate diffusion and ion transport in the organic liquid electrolyte phase for such batteries. Results from Raman and NMR spectroscopy showed higher mobility of $\mathrm{NaPF}_{6}$ compared to LiPF6 in the EC: EMC mixtures [118]. The diffusion of the TFSI ${ }^{-}$anions in the above solutions was measured using a pulsed gradient spin-echo NMR (PGSE-NMR) [168]. It was observed that the PC diffusion coefficient was higher in the $1 \mathrm{M} \mathrm{NaTFSI-PC}$ solution than that in the $1 \mathrm{M}$ LiTFSI-PC solution. A higher discrepancy in the value of the PC diffusion coefficient was observed for the $2 \mathrm{M}$ solutions. However, the TFSI- diffusion coefficient in $1 \mathrm{M} \mathrm{NaTFSI-PC}$ solution 
was higher than that in the $1 \mathrm{M}$ LiTFSI-PC solution, but only in the $353-313 \mathrm{~K}$ range; their diffusion coincided at lower temperatures. The experimentally measured ionic conductivity of the $1 \mathrm{M}$ NaTFSI-PC solutions was higher than that of the $1 \mathrm{M}$ LiTFSI-PC solutions in very dilute $(\leq 0.25 \mathrm{M})$ or highly concentrated solutions (1.5 M, $2 \mathrm{M})$ [168]. In addition, it was shown that the viscosity $(\eta)$ of $1 \mathrm{M} \mathrm{NaTFSI-PC}$ solutions was lower than that of the $1 \mathrm{M}$ LiTFSI-PC solutions in the temperature range of 353-283 K [168].

Furthermore, the binary diffusion coefficients of $\mathrm{NaPF}_{6}-\mathrm{EC}: \mathrm{DEC}$ solutions, for different concentrations, were calculated and compared to that of $\mathrm{LiPF}_{6}-\mathrm{EC}: \mathrm{DEC}$ solutions by Landesfeind et al. (Figure 9) [169]. It was observed a higher binary diffusion coefficient $\left(D_{ \pm}\right), \mathrm{Na}^{+}$transference number, and ionic conductivity for the $\mathrm{NaPF}_{6}-\mathrm{EC}: \mathrm{DEC}$ solution, specifically at higher salt concentrations $(1 \mathrm{M})$, compared to the corresponding values to the $\mathrm{LiPF}_{6}-\mathrm{EC}: \mathrm{DEC}$ solutions, due to the weaker electrostatic interaction of the larger $\mathrm{Na}^{+}$cation [169].
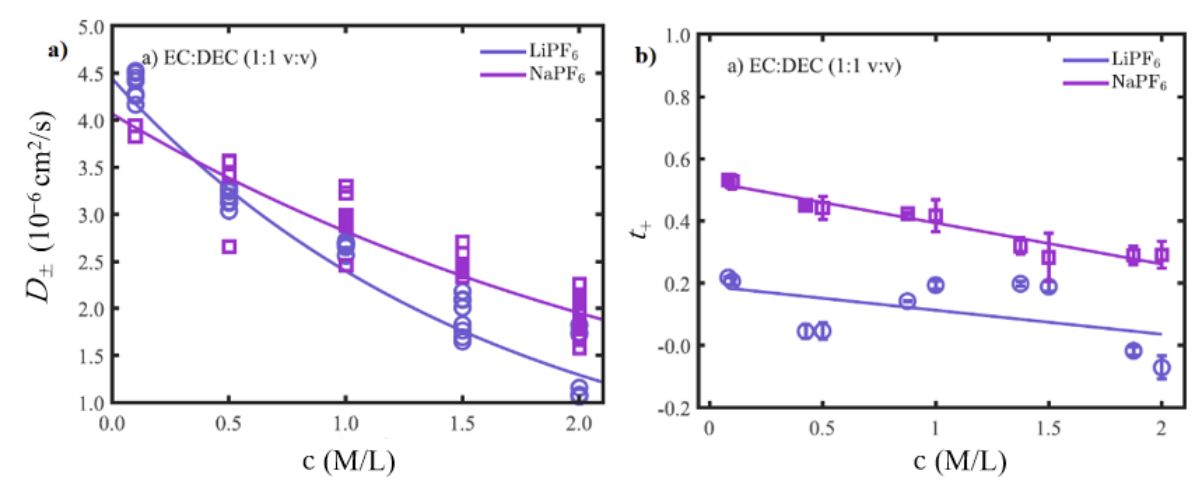

Figure 9 (a) Binary diffusion coefficients of $\mathrm{LiPF}_{6}$ and $\mathrm{NaPF}_{6}$ in EC: DEC (1:1 v: v, 5 wt\% FEC was added to sodium electrolytes in coin cells) determined at $25{ }^{\circ} \mathrm{C}$ in symmetric coin cells. The solid lines represent fits to the equation: $D_{ \pm}=p_{1} \cdot \exp \left(-p_{2} c\right) 10^{-6} \mathrm{~cm}^{2} / \mathrm{s},(\mathrm{b})$ Transference numbers of the previous solutions. The solid lines are based on the equation: $t_{+}=p_{1}+p_{2} \cdot c$ Reprinted with permission from the article by Landesfeind et al. [169], Copyright 2021 Institute Physics and IOP Publishing.

In addition, at high concentrations, higher conductivities were observed for the electrolytes containing larger amounts of $\mathrm{Na}^{+}$cation [73]. This trend was explained by the different viscosities of the electrolyte due to the weaker interaction between the larger $\mathrm{Na}^{+}$ion and the solvent/ $\mathrm{PF}_{6}{ }^{-}$[73]. This was also observed in a previous study for $\mathrm{NaClO}_{4}\left(\mathrm{LiClO}_{4}\right)-\mathrm{PC}$ solutions for concentrations above $1 \mathrm{M}$ [170]. Furthermore, the formation of ion pairs at high salt concentrations could reduce the free charge carriers $[15,19,105,171]$.

Morales et al. studied the viscosity and ionic conductivity of $1 \mathrm{M} \mathrm{NaPF}_{6}$ in the binary EC: PC mixture (1:1), and the ternary 5EC:3PC:2DEC (5:3:2) mixture, including versions with 2 wt\% fluoroethylene carbonate (FEC). Both the viscosity and the conductivity were found to follow the VFT relation. The 5EC:3PC:2DEC electrolyte exhibited lower viscosity due to the lower concentration of the more viscous PC solvent and the addition of the DEC solvent with its lower viscosity. The order of the ionic conductivity, in terms of the solvent mixtures, was 5EC:3PC:2DEC + FEC > 5EC:3PC:2DEC $\geq E C: P C \geq E C: P C+F E C$, which was the inverse of the viscosity trend and could depict the role of viscosity in the ion dynamics. However, at high temperatures, the ionic conductivity values were observed to be similar. Further, the Walden products (product of the molar ionic conductivity and 
solution viscosity), which were used for assessing the ion transport in ionic liquids, were calculated and observed to lie below the Walden ideal line. It was concluded from this interesting set of experiments that by reducing the ion-ion and ion-solvent interactions, the ion dynamics (mobility) would be enhanced [172]. Furthermore, for the KIB solutions, the $\mathrm{KN}\left(\mathrm{SO}_{2} \mathrm{~F}\right)_{2}$ salt appeared to have the highest solubility in the carbonate-ester and ether solvents among $\mathrm{KN}\left(\mathrm{SO}_{2} \mathrm{~F}\right)_{2}, \mathrm{KN}\left(\mathrm{SO}_{2} \mathrm{CF}_{3}\right)_{2}, \mathrm{KPF}_{6}$, $\mathrm{KBF}_{4}$, and $\mathrm{KClO}_{4}$ salts. In addition, the $\mathrm{KN}\left(\mathrm{SO}_{2} \mathrm{~F}\right)_{2}-\mathrm{DME}$ solution presented a higher ionic conductivity and lower viscosity in the highly concentrated region compared to the corresponding values for $\mathrm{KN}\left(\mathrm{SO}_{2} \mathrm{~F}\right)_{2}-\mathrm{PC}, \mathrm{KN}\left(\mathrm{SO}_{2} \mathrm{~F}\right)_{2}-\mathrm{GBL}$, and $\mathrm{KN}\left(\mathrm{SO}_{2} \mathrm{CF}_{3}\right)_{2}-\mathrm{DME}$ solutions [173].

\subsection{Simulations}

In this section, we will focus on the atomistic modeling studies of electrolytes conducted for NIBS [3] and KIBs [20, 173]. It was shown by Pham et al. [133] that the short-scale dynamics, up to 10 ps, of the $\mathrm{Na}^{+}$ion in $\mathrm{EC}$ was faster than that of the $\mathrm{Li}^{+}$or $\mathrm{K}^{+}$ion due to its weaker solvation (Figure 10).

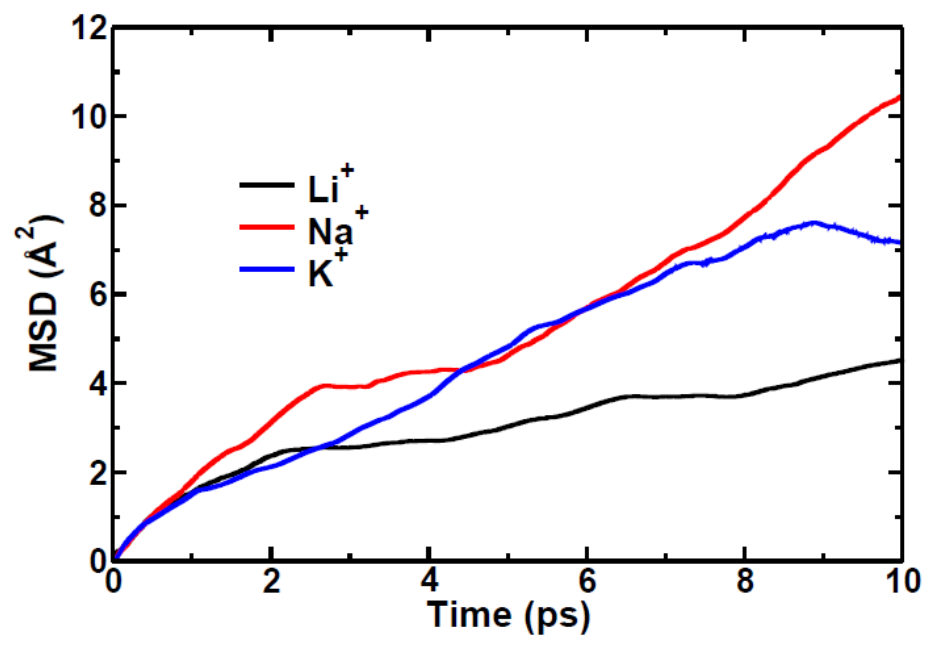

Figure 10 Mean square displacement (MSD) as a function of time, computed for the $\mathrm{Li}^{+}$ (black), $\mathrm{Na}^{+}$(red), and $\mathrm{K}^{+}$(blue) ions in the EC solvent [133]. Reprinted with permission from the article by Pham et al. Copyright 2017 American Chemical Society.

Large scale quantum MD simulations of NaFSA-DME electrolyte solutions with salt concentrations of $5 \%, 10 \%$, and $40 \%$ (superconcentrated solution) were investigated by Okoshi et al. [174]. The diffusion coefficients were extracted by simulations of $20 \mathrm{ps,}$, and for the $5 \%$ solution, the DME calculated diffusion agreed with the experimental measurements [31, 175]. In the superconcentrated solution, the vehicular type of diffusion was prohibited, and the alternative pathway was the dissociation/association reactions [176] between the carrier ion and the solvent/anion. It was also shown that the ligand exchange reactions were responsible for the carrier diffusion in the superconcentrated solution. Such reactions were between 60-120 ps in the electrolyte solutions.

In a classical MD study of $\mathrm{NaPF}_{6}-\mathrm{EC}$ solution (for $1 \mathrm{M} \mathrm{NaPF}_{6}$ concentration), it was shown that the self-diffusion of ions increases with temperature and follows an Arrhenius type of relation (Equation (14)) [177]. In an extensive classical MD study of $\mathrm{NaClO}_{4}$ salts in various solvents, the transference number was observed to depend on the relative mobility of $\mathrm{Na}^{+}$to its counterion $\mathrm{ClO}_{4}^{-}$and was calculated, by MD, for a range of cyclic, linear solvents, or mixtures of them [178]. 
The $\mathrm{Na}^{+}$transference number varied from 0.3 to 0.51 depending on the solvent. The EC based solvents exhibited a high $\mathrm{Na}^{+}$transference number of $\approx 0.5$. The ionic conductivity of the solvent depended on its dielectric constant since it dictated the degree association of the salts, and the viscosity of the solvent, which was inversely proportional to the ion mobility [178].

The $\mathrm{Na}^{+}$diffusion coefficient in DME solutions (having $\mathrm{TFSI}^{-}$as anions) was predicted quantitatively, corresponding to the experimental values [132], using the classical MD simulations based on a polarized force field at $298 \mathrm{~K}$. The $\mathrm{Na}^{+}$transference number was predicted to be $0.45-$ 0.5 depending on the salt concentration (0.5-2 M) [132]. The $\mathrm{Na}^{+}$transport mechanism was less vehicular than that of $\mathrm{Li}^{+}$in the DME solutions. For a given salt concentration, higher diffusion coefficients were predicted for NaTFSI than for LiTFSI in DME solutions (Figure 11) [132].
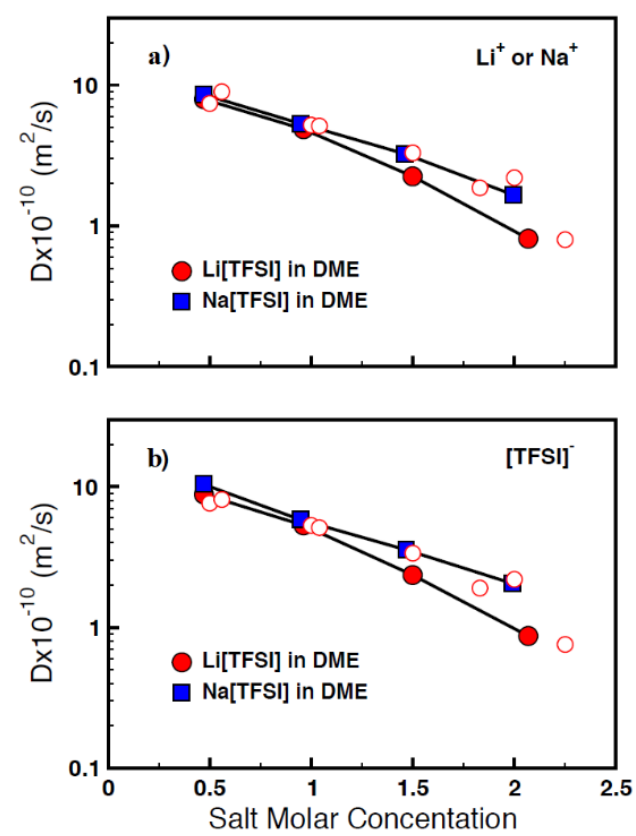

Figure 11 Self-diffusion coefficients of $\mathrm{Li}^{+} \mathrm{TFSI}^{-}$in DME (circles) and $\mathrm{Na}^{+} \mathrm{TFSI}^{-}$in DME (squares) as a function of the salt concentration for (a) $\mathrm{Li}^{+}$or $\mathrm{Na}^{+}$and (b) $\mathrm{TFSI}^{-}$. The computational results are represented by the filled symbols. Reprinted with permission from the article by Liyana-Arachchi et al. [132] Copyright 2017 American Chemical Society.

\section{Transport in $\mathrm{Ca}-/ \mathrm{Mg}-/ \mathrm{Zn}-/ \mathrm{Al}-$ ion Batteries}

\subsection{Experiments}

Multivalent metal ion batteries such as Mg-ion batteries (MIBs) $[179,180]$, Ca-ion batteries (CIBs) [181], Zn-ion batteries (ZIBs) [4, 182], and Al-ion batteries (AIBs) [183-185] have been considered as the future battery systems for large-scale energy storage with promising electrolyte systems identified [4, 182, 186-188]. However, a heavier ion generally has the disadvantage of lower diffusion.

The experimental work conducted by Seki et al. demonstrated that $\mathrm{Mg}^{2+}$ formed a much stable complex with PC and TFSA ${ }^{-}$anion than $\mathrm{Ca}^{2+}$ (Figure 12) [168]. Hence, the diffusion coefficient of PC and TFSA ${ }^{-}$was lower when the cation was $\mathrm{Mg}^{2+}$ than when it was $\mathrm{Ca}^{2+}$. The same study revealed that 
the interaction energy between the metal cations and PC solvent and TFSA ${ }^{-}$anion increased in the order $\mathrm{Na}^{+}<\mathrm{Li}^{+}<\mathrm{Ca}^{2+}<\mathrm{Mg}^{2+}$. Thus, for the same salt concentration, the self-diffusion coefficient of PC and TFSA ${ }^{-}$anion exhibited the order $\mathrm{Na}^{+}>\mathrm{Li}^{+}>\mathrm{Ca}^{2+}>\mathrm{Mg}^{2+}$. However, it was not feasible to experimentally measure the self-diffusion coefficient of divalent and sodium cations [168]. The selfdiffusion coefficients were found to monotonically decrease with increasing salt concentration. A larger salt concentration dependence of the self-diffusion coefficient was observed for solutions with divalent cations than in solutions with monovalent cations [168]. The temperature dependence of the self-diffusion coefficient and ionic conductivity followed an Arrhenius type behavior. The maximum ionic conductivity was observed for 0.5 and $1 \mathrm{M}$ salt concentrations for all electrolyte solutions (Figure 13a). The NaTFSA electrolyte showed the highest ionic conductivity for all salt concentrations since it had the lowest viscosity, $\eta$, for all the salt systems.
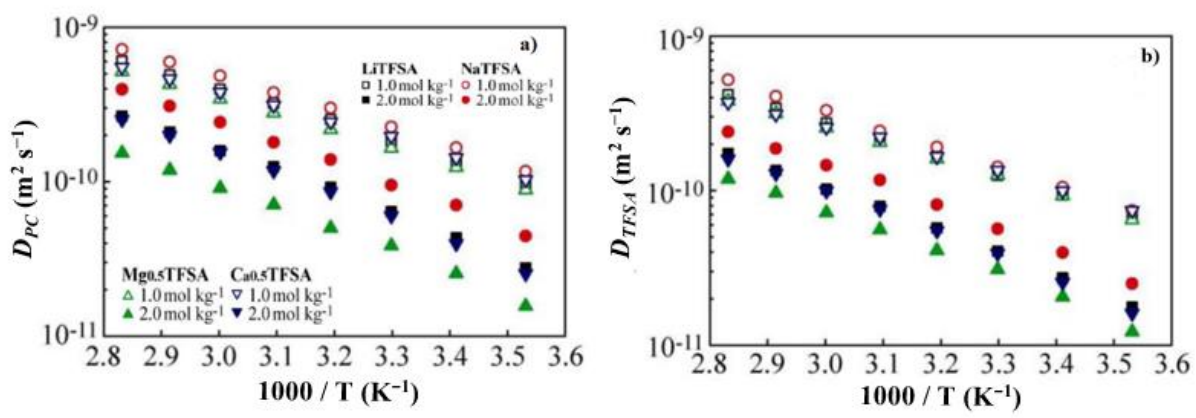

Figure 12 Temperature dependence of the self-diffusion coefficients of (a) PC and (b) TFSA anion for electrolyte solutions containing PC and various $\mathrm{Li}$ (or $\mathrm{Na}$ ) concentrations [168]. Reprinted with permission from the article by Seki et al. Copyright 2018 Institute Physics and IOP Publishing.
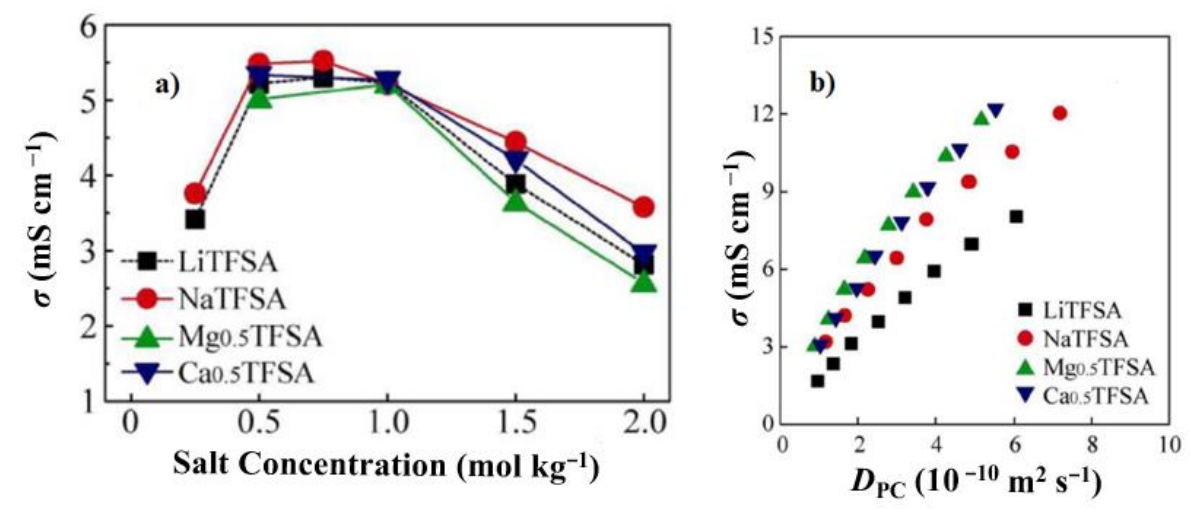

Figure 13 (a) Dependence of the ionic conductivity, $\sigma$, on the salt concentration at 303.15 K for electrolyte solutions containing PC and various TFSA salts. (b) Self-diffusion coefficient of PC and the ionic conductivity for electrolyte solutions of PC and various TFSA salts [168]. Reprinted with permission from the article by Seki et al. Copyright 2018 IOP Publishing.

In addition, the relationship between the self-diffusion coefficient of PC (DPC) and ionic conductivity can be seen in Figure 13b. In particular, the order of the ionic conductivity with both 
$\eta^{-1}$ and $D_{P C}$ were $\mathrm{Mg}(\mathrm{TFSA})_{2} \geq \mathrm{Ca}(\mathrm{TFSA})_{2}>\mathrm{NaTFSA}>$ LiTFSA, which means that the divalent cation solutions have higher conductivity than the monovalent cation solutions for the same viscosity [168].

\subsection{Simulations}

In this section, we focus on the atomistic modeling studies of electrolytes for $\mathrm{Mg}^{2+}, \mathrm{Zn}^{2+}, \mathrm{Ca}^{2+}$, and $\mathrm{Al}^{3+}$ ion batteries. A theoretical investigation performed by Okoshi et al. showed that the divalent $\mathrm{Mg}^{2+}$ ion has a stronger solvation structure with different organic electrolytes compared to the monovalent $\mathrm{Li}^{+}$and $\mathrm{Na}^{+}[166,174]$. Likewise, $\mathrm{Mg}^{2+}$ and $\mathrm{Ca}^{2+}$ in the mixture of $\mathrm{PC}$ and EC electrolyte solutions consisted of stronger cation-carbonate interactions than $\mathrm{Li}^{+}$and $\mathrm{Na}^{+}$in the same solutions [3]. Classical $\mathrm{MD}$ and $a b$ initio simulations of $\mathrm{Mg}^{2+}$ and $\mathrm{Ca}^{2+}$ in the $\mathrm{EC}$, vinylene carbonate (VC), PC, butylene carbonate (BC), DMC, EMC, DEC, EC:PC, EC:PC, EC:EMC, and EC:DEC solutions demonstrated that $\mathrm{Mg}^{2+}$ and $\mathrm{Ca}^{2+}$ could be more soluble in these electrolytes than $\mathrm{Li}^{+}$and $\mathrm{Na}^{+}[54,178,189,190]$. Therefore, the values of the ionic mobility of the divalent in the same solvents were 1.7 and $1.5 \mathrm{mS} / \mathrm{cm}$, respectively. However, when the concentration was increased to $1 \mathrm{M}$, the conductivity values changed inversely. At $1.0 \mathrm{M}$ concentration, the ionic conductivity of $\mathrm{Li}^{+}$, $\mathrm{Na}^{+}, \mathrm{Mg}^{2+}$, and $\mathrm{Ca}^{2+}$ was $6.3,6.9,1.9$, and $2.8 \mathrm{mS} / \mathrm{cm}$, respectively. The divalent cation $\mathrm{Mg}^{2+}$ consisted of a higher polarizing power than $\mathrm{Ca}^{2+}$ and exhibited lower ionic conductivity. The experimental, classical MD simulations and first principle studies demonstrated that the diffusion coefficient of the $\mathrm{Mg}^{2+}$ had been changed by changing the anions in the same organic electrolytes, with the order $\mathrm{Mg}\left(\mathrm{BH}_{4}\right)_{2}>\mathrm{Mg}\left(\mathrm{BF}_{4}\right)_{2}>\mathrm{Mg}(\mathrm{TFSI})_{2}$ [191]. Furthermore, it was revealed that the solvation of the $\mathrm{Mg}^{2+}$ ion in the different organic electrolytes was not necessarily related to the dielectric constant of the solvent molecules, although it had an intricate relationship with the molecular size of the solvents. In addition, it has also been reported that increasing the concentration of $\mathrm{Mg}^{2+}$ in the organic electrolyte solutions could decrease the diffusion coefficient of $\mathrm{Mg}^{2+}$ by cluster formation [192].

DFT calculation by $\mathrm{Li}$ et al. demonstrated that $\mathrm{Zn}^{2+}$ could adjoin the TFSI- anion more strongly compared to $\mathrm{Mg}^{2+}$, and thus, in organic electrolytes, $\mathrm{Zn}^{2+}$ had more ion-ion association than $\mathrm{Mg}^{2+}$ [193]. Experimental and MD simulations showed that $\mathrm{Mg}^{2+}$ and $\mathrm{Zn}^{2+}$ had almost the same cationoxygen distance with the TFSI anion $[191,194]$. This was mainly because of the similar cationic

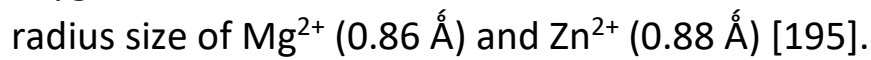

The dynamics of $\mathrm{Zn}^{2+}$ ion in the organic electrolyte systems was directly related to the viscosity, dielectric constant, molecular geometry, and interaction strength between cation-solvent and cation-anion $[191,196]$. The computational and experimental work by Han et al. showed that the diffusion coefficient of $\mathrm{Zn}^{2+}$ ions was directly influenced by the viscosity and dielectric constant of the different aprotic solvents, as depicted in Figure 14 [197]. As can be seen from the figure, the cations and the anions of the $\mathrm{Zn}(\mathrm{TFSI})_{2}$ and $\mathrm{Zn}\left(\mathrm{CF}_{3} \mathrm{SO}_{3}\right)_{2}$ salts in the $\mathrm{PC}$ solvent showed the lowest diffusion coefficient and conductivity compared to the other aprotic solvents, probably due to their highest dielectric constant and viscosity difference among the various organic electrolytes [198]. Therefore, it was assumed that the reduction in the viscosity difference of the organic solvent could increase the transportation of the $\mathrm{Zn}^{2+}$ ion. The introduction of DMC in the $0.5 \mathrm{M} \mathrm{Zn}^{2+}$ in a trimethyl phosphate (TMP) solution increased the conductivity from $4.58 \mathrm{mS} / \mathrm{cm}$ to $4.90 \mathrm{mS} / \mathrm{cm}$ by reducing the viscosity of the original solvent [199]. 


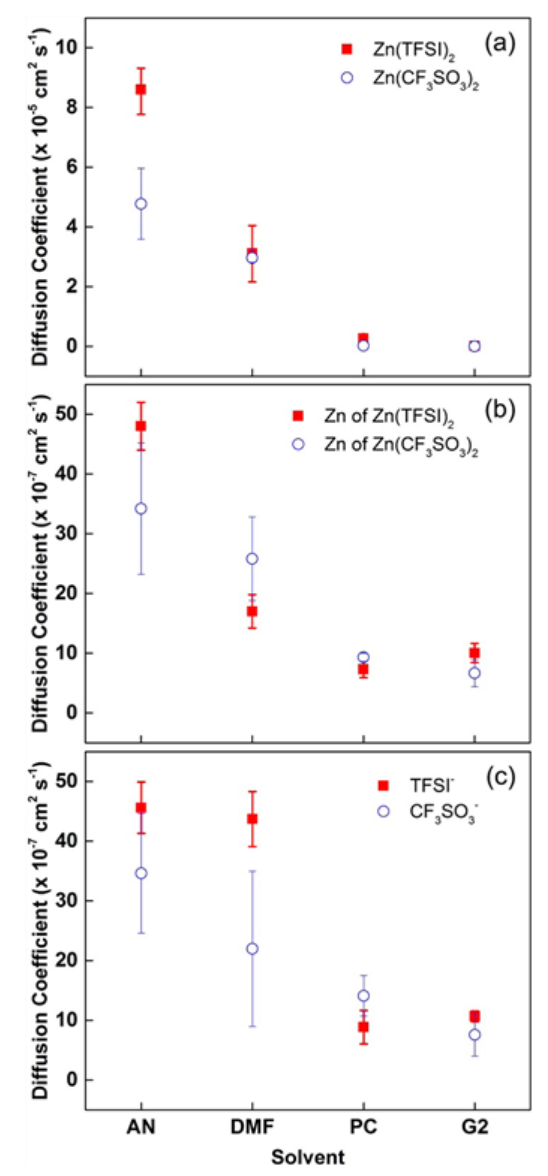

Figure 14 Isothermal diffusion coefficients of (a) $\mathrm{Zn}(\mathrm{TFSI})_{2}$ and $\mathrm{Zn}\left(\mathrm{CF}_{3} \mathrm{SO}_{3}\right)_{2}$ (from experimental estimation methods at $25^{\circ} \mathrm{C}$ ), (b) $\mathrm{Zn}^{2+}$ cations, and (c) $\mathrm{TFSI}^{-}$and $\mathrm{CF}_{3} \mathrm{SO}_{3}{ }^{-}$ anions of $0.1 \mathrm{M} \mathrm{Zn}(\mathrm{TFSI})_{2}$ and $\mathrm{Zn}\left(\mathrm{CF}_{3} \mathrm{SO}_{3}\right)_{2}$ electrolytes with acetonitrile, dimethylformamide, PC, and diglyme (G2) [197]. Reprinted with permission from the article by Han et al. Copyright 2016 American Chemical Society.

\section{Conclusions}

In this article, we have reviewed studies on ion and solvent transport in the organic liquid electrolyte phase that are used for lithium batteries and beyond. The diffusion mechanisms and the transference number, which can strongly govern the battery performance, are challenging and nontrivial to access experimentally $[6,8]$. Although extensive experimental studies focusing on lithium-ion batteries have been conducted, only a limited number of studies focusing on sodium, potassium, and divalent metal ion batteries have been done. This could not only be due to the difficulty of experimentally measuring sodium, potassium, and other cation diffusivities, but also due to the lack of appropriate atomistic computational models since it is well known that nonpolarizable force fields underpredict diffusion by approximately few orders of magnitude. In principle, polarizable force fields could quantitatively predict the diffusion mechanism, the transference number, and the ionic conductivity, but their calculations are computationally demanding and their development and implementation are currently still limited only to lithium electrolytes. An alternative to the polarizable force fields would be the use of non-polarizable force fields with parametrized charge scaling based on the experimental diffusivity and conductivity data. Such models would be successful in shedding light on the cation transport mechanism and the 
quantitative prediction of diffusion for the simple lithium electrolyte solutions. However, to date, such methodology has not been applied in solutions used in divalent or trivalent $\left(\mathrm{Mg}^{2+}, \mathrm{Al}^{3+}\right.$, etc.) ion batteries, in which the electrostatic interactions are stronger, and therefore more challenging for the success of this method. However, taking into account the increasing demand for new batteries containing ions that are more abundant in nature than lithium, such as $\mathrm{Na}^{+}, \mathrm{K}^{+}, \mathrm{Mg}^{2+}$, etc. more research efforts should be devoted to studying their ion transport. In addition, the development of appropriate atomistic computational models could prove to help shed light on the diffusion mechanisms and the concentration and temperature dependence of ion transport and thus help in speeding up the design of such next generation batteries. Another issue would be the accurate atomistic modeling of solvent mixtures (binary or high order) that are excessively used as organic solutions. Future efforts should also focus on identifying co-solvents [200] that adequately reduce ion aggregation while simultaneously facilitating rapid metal-ion migration in the electrolyte phase to improve the performance of the battery. Even modest improvements in the transference number, e.g., to $t_{+} \approx 0.6-0.7$, would be beneficial by allowing an increase in the energy density and high charge rates.

\section{Author Contributions}

Conceptualization, A.K.;Funding acquision, A.K.;Investigation, A.K., Md.S.K., C.Y., R.D., K.U., T.O., Q.C., Project administration, A.K.; Writing original draft, A.K., Md.S.K., C.Y, R.D., K.U., T.O., Q.C. All authors have read and agreed to the published version of the manuscript.

\section{Funding}

Funding support from Luxembourg Institute of Science \& Technology and EPSRC (Engineering and Physical Sciences Council) under the grant number EP/M027066/1 and EP/R021554/2 are acknowledged.

\section{Competing Interests}

The authors have declared that no competing interests exist.

\section{References}

1. Weiss M, Ruess R, Kasnatscheew J, Levartovsky $Y$, Levy NR, Minnmann P, et al. Fast charging of lithium-ion batteries: A review of materials aspects. Adv Energy Mater. 2021; 11: 2101126.

2. Ponrouch A, Marchante E, Courty M, Tarascon JM, Palacin MR. In search of an optimized electrolyte for Na-ion batteries. Energy Environ Sci. 2012; 5: 8572-8583.

3. Ponrouch A, Monti D, Boschin A, Steen B, Johansson P, Palacín MR. Non-aqueous electrolytes for sodium-ion batteries. J Mater Chem A. 2015; 3: 22-42.

4. Zhang J, Yao X, Misra RK, Cai Q, Zhao Y. Progress in electrolytes for beyond-lithium-ion batteries. J Mater Sci Technol. 2020; 44: 237-257.

5. Li Q, Chen J, Fan L, Kong X, Lu Y. Progress in electrolytes for rechargeable Li-based batteries and beyond. Green Energy Environ. 2016; 1: 18-42.

6. Diederichsen KM, McShane EJ, McCloskey BD. Promising routes to a high $\mathrm{Li}^{+}$transference number electrolyte for lithium ion batteries. ACS Energy Lett. 2017; 2: 2563-2575. 
7. von Cresce A, Xu K. Preferential solvation of $\mathrm{Li}^{+}$directs formation of interphase on graphitic anode. Electrochem Solid State Lett. 2011; 14: A154.

8. Marcus Y, Hefter G. Ion pairing. Chem Rev. 2006; 106: 4585-4621.

9. Zugmann S, Fleischmann $M$, Amereller $M$, Gschwind RM, Wiemhöfer HD, Gores HJ. Measurement of transference numbers for lithium ion electrolytes via four different methods, a comparative study. Electrochim Acta. 2011; 56: 3926-3933.

10. Biggs MJ, Buts A. Virtual porous carbons: What they are and what they can be used for. Mol Simul. 2006; 32: 579-593.

11. Barthel J, Ströder U, Iberl L, Hammer H. The temperature dependence of the properties of electrolyte solutions. IV. Determination of cationic transference numbers in methanol, ethanol, propanol, and acetonitrile at various temperatures. Ber Bunsen Ges Phys Chem. 1982; 86: 636645.

12. Lundgren $H$, Behm $M$, Lindbergh $G$. Electrochemical characterization and temperature dependency of mass-transport properties of LiPF 6 in EC:DEC. J Electrochem Soc. 2014; 162: A413.

13. Jouyban A, Soltanpour S. Prediction of dielectric constants of binary solvents at various temperatures. J Chem Eng Data. 2010; 55: 2951-2963.

14. Hall DS, Self J, Dahn JR. Dielectric constants for quantum chemistry and Li-ion batteries: Solvent blends of ethylene carbonate and ethyl methyl carbonate. J Phys Chem C. 2015; 119: 2232222330.

15. Feng Z, Higa K, Han KS, Srinivasan V. Evaluating transport properties and ionic dissociation of $\mathrm{LiPF}_{6}$ in concentrated electrolyte. J Electrochem Soc. 2017; 164: A2434-A2440.

16. Hayamizu K. Direct relations between ion diffusion constants and ionic conductivity for lithium electrolyte solutions. Electrochim Acta. 2017; 254: 101-111.

17. Hayamizu K. 7Li spin-echo NMR diffusion studies. Annu Rep NMR Spectrosc. 2019; 98: 57-123.

18. Borodin O, Olguin M, Ganesh P, Kent PR, Allen JL, Henderson WA. Competitive lithium solvation of linear and cyclic carbonates from quantum chemistry. Phys Chem Chem Phys. 2016; 18: 164175.

19. Seo DM, Reininger S, Kutcher M, Redmond K, Euler WB, Lucht BL. Role of mixed solvation and ion pairing in the solution structure of lithium ion battery electrolytes. J Phys Chem C. 2015; 119: 14038-14046.

20. Okoshi M, Yamada Y, Komaba S, Yamada A, Nakai H. Theoretical analysis of interactions between potassium ions and organic electrolyte solvents: A comparison with lithium, sodium, and magnesium ions. J Electrochem Soc. 2016; 164: A54-A60.

21. Kulova TL, Skundin AM. From lithium-ion to sodium-ion battery. Russ Chem Bull. 2017; 66: 13291335.

22. Vignarooban K, Kushagra R, Elango A, Badami P, Mellander BE, Xu X, et al. Current trends and future challenges of electrolytes for sodium-ion batteries. Int J Hydrog Energy. 2016; 41: 28292846.

23. Ohba T, Kaneko K. Competition of desolvation and stabilization of organic electrolytes in extremely narrow nanopores. J Phys Chem C. 2013; 117: 17092-17098.

24. Tang J, Dysart AD, Pol VG. Advancement in sodium-ion rechargeable batteries. Curr Opin Chem Eng. 2015; 9: 34-41.

25. Delmas C. Sodium and sodium-ion batteries: 50 years of research. Adv Energy Mater. 2018; 8: 
1703137.

26. Che $H$, Chen S, Xie Y, Wang H, Amine K, Liao XZ, et al. Electrolyte design strategies and research progress for room-temperature sodium-ion batteries. Energy Environ Sci. 2017; 10: 1075-1101.

27. Zhang W, Liu Y, Guo Z. Approaching high-performance potassium-ion batteries via advanced design strategies and engineering. Sci Adv. 2019; 5: eaav7412.

28. Hosaka T, Kubota K, Hameed AS, Komaba S. Research development on K-ion batteries. Chem Rev. 2020; 120: 6358-6466.

29. Rajagopalan R, Tang $\mathrm{Y}$, Ji X, Jia C, Wang H. Advancements and challenges in potassium ion batteries: A comprehensive review. Adv Funct Mater. 2020; 30: 1909486.

30. Xu K. Nonaqueous liquid electrolytes for lithium-based rechargeable batteries. Chem Rev. 2004; 104: 4303-4418.

31. Hayamizu K, Aihara Y, Arai S, Martinez CG. Pulse-gradient spin-echo $1 \mathrm{H}, 7 \mathrm{Li}$, and 19F NMR diffusion and ionic conductivity measurements of 14 organic electrolytes containing LiN( $\left(\mathrm{SO}_{2} \mathrm{CF}_{3}\right)_{2}$. J Phys Chem B. 1999; 103: 519-524.

32. Li Q, Jiao S, Luo L, Ding MS, Zheng J, Cartmell SS, et al. Wide-temperature electrolytes for lithium-ion batteries. ACS Appl Mater Interfaces. 2017; 9: 18826-18835.

33. Jow TR, Ding MS, Xu K, Zhang SS, Allen JL, Amine K, et al. Nonaqueous electrolytes for widetemperature-range operation of Li-ion cells. J Power Sources. 2003; 119: 343-348.

34. Smart MC, Ratnakumar BV, Whitcanack LD, Chin KB, Surampudi S, Croft H, et al. Improved lowtemperature performance of lithium-ion cells with quaternary carbonate-based electrolytes. J Power Sources. 2003; 119: 349-358.

35. Gores HJ, Barthel J, Zugmann S, Moosbauer D, Amereller M, Hartl R, et al. Handbook of battery materials. Weinheim: Wiley; 2011.

36. Stejskal EO, Tanner JE. Spin diffusion measurements: Spin echoes in the presence of a timedependent field gradient. J Chem Phys. 1965; 42: 288-292.

37. Hahn EL. Spin echoes. Phys Rev. 1950; 80: 580-594.

38. Morris KF, Johnson Jr CS. Diffusion-ordered two-dimensional nuclear magnetic resonance spectroscopy. J Am Chem Soc. 1992; 114: 3139-3141.

39. Pelta MD, Barjat H, Morris GA, Davis AL, Hammond SJ. Pulse sequences for high-resolution diffusion-ordered spectroscopy (HR-DOSY). Magn Reson Chem. 1998; 36: 706-714.

40. Pagès G, Gilard V, Martino R, Malet-Martino M. Pulsed-field gradient nuclear magnetic resonance measurements (PFG NMR) for diffusion ordered spectroscopy (DOSY) mapping. Analyst. 2017; 142: 3771-3796.

41. Carr HY, Purcell EM. Effects of diffusion on free precession in nuclear magnetic resonance experiments. Phys Rev. 1954; 94: 630-638.

42. Tanner JE. Use of the stimulated echo in NMR diffusion studies. J Chem Phys. 1970; 52: 25232526.

43. Hinton DP, Johnson Jr CS. Diffusion ordered 2D NMR spectroscopy of phospholipid vesicles: Determination of vesicle size distributions. J Phys Chem. 1993; 97: 9064-9072.

44. Gibbs SJ, Johnson Jr CS. A PFG NMR experiment for accurate diffusion and flow studies in the presence of eddy currents. J Magn Reson. 1991; 93: 395-402.

45. Johnson Jr CS. Diffusion ordered nuclear magnetic resonance spectroscopy: Principles and applications. Prog Nucl Magn Reson Spectrosc. 1999; 34: 203-256.

46. Schmidt F, Schönhoff M. Solvate cation migration and ion correlations in solvate ionic liquids. J 
Phys Chem B. 2020; 124: 1245-1252.

47. Engelke S, Marbella LE, Trease NM, De Volder M, Grey CP. Three-dimensional pulsed field gradient NMR measurements of self-diffusion in anisotropic materials for energy storage applications. Phys Chem Chem Phys. 2019; 21: 4538-4546.

48. Su CC, He M, Amine R, Chen Z, Amine K. Internally referenced DOSY-NMR: A novel analytical method in revealing the solution structure of lithium-ion battery electrolytes. J Phys Chem Lett. 2018; 9: 3714-3719.

49. Su CC, He M, Amine R, Rojas T, Cheng L, Ngo AT, et al. Solvating power series of electrolyte solvents for lithium batteries. Energy Environ Sci. 2019; 12: 1249-1254.

50. Schmidt F, Pugliese A, Santini CC, Castiglione F, Schönhoff M. Spectral deconvolution in electrophoretic NMR to investigate the migration of neutral molecules in electrolytes. Magn Reson Chem. 2020; 58: 271-279.

51. Krachkovskiy SA, Pauric AD, Halalay IC, Goward GR. Slice-selective NMR diffusion measurements: A robust and reliable tool for in situ characterization of ion-transport properties in lithium-ion battery electrolytes. J Phys Chem Lett. 2013; 4: 3940-3944.

52. Hallberg F, Furó I, Yushmanov PV, Stilbs P. Sensitive and robust electrophoretic NMR: Instrumentation and experiments. J Magn Reson. 2008; 192: 69-77.

53. Pettersson E, Furo I, Stilbs P. On experimental aspects of electrophoretic NMR. Concepts Magn Reson Part A Educ J. 2004; 22: 61-68.

54. Shakourian-Fard M, Kamath G, Smith K, Xiong H, Sankaranarayanan SK. Trends in Na-ion solvation with alkyl-carbonate electrolytes for sodium-ion batteries: Insights from firstprinciples calculations. J Phys Chem C. 2015; 119: 22747-22759.

55. Krachkovskiy SA, Bazak JD, Fraser S, Halalay IC, Goward GR. Determination of mass transfer parameters and ionic association of $\mathrm{LiPF}_{6}$ : Organic carbonates solutions. J Electrochem Soc. 2017; 164: A912.

56. Kühnel RS, Balducci A. Lithium ion transport and solvation in N-butyl-N-methylpyrrolidinium bis (trifluoromethanesulfonyl) imide-propylene carbonate mixtures. J Phys Chem C. 2014; 118: 5742-5748.

57. Valøen LO, Reimers JN. Transport properties of LiPF 6 -based Li-ion battery electrolytes. J Electrochem Soc. 2005; 152: A882-A891.

58. Hafezi $\mathrm{H}$, Newman J. Verification and analysis of transference number measurements by the galvanostatic polarization method. J Electrochem Soc. 2000; 147: 3036.

59. Stewart SG, Newman J. The use of UV/vis absorption to measure diffusion coefficients in LiPF 6 electrolytic solutions. J Electrochem Soc. 2007; 155: F13.

60. Nyman A, Behm M, Lindbergh G. Electrochemical characterisation and modelling of the mass transport phenomena in LiPF 6 -EC-EMC electrolyte. Electrochim Acta. 2008; 53: 6356-6365.

61. Harned HS, French DM. A conductance method for the determination of the diffusion coefficients of electrolytes. Ann N Y Acad Sci. 1945; 46: 267-284.

62. Newman J, Chapman TW. Restricted diffusion in binary solutions. AIChE J. 1973; 19: 343-348.

63. Ehrl A, Landesfeind J, Wall WA, Gasteiger HA. Determination of transport parameters in liquid binary electrolytes: Part II. Transference number. J Electrochem Soc. 2017; 164: A2716-A2731.

64. Ehrl A, Landesfeind J, Wall WA, Gasteiger HA. Determination of transport parameters in liquid binary lithium ion battery electrolytes: Part \{1\}. Diffusion coefficient. J Electrochem Soc. 2017; 164: A826. 
65. Zhao J, Wang L, He X, Wan C, Jiang C. Determination of lithium-ion transference numbers in $\mathrm{LiPF}_{6}-\mathrm{PC}$ solutions based on electrochemical polarization and NMR measurements. J Electrochem Soc. 2008; 155: A292.

66. Bruce PG, Vincent CA. Steady state current flow in solid binary electrolyte cells. J Electroanal Chem Interfacial Electrochem. 1987; 225: 1-17.

67. Bruce PG, Hardgrave MT, Vincent CA. The determination of transference numbers in solid polymer electrolytes using the Hittorf method. Solid State Ion. 1992; 53: 1087-1094.

68. Farkhondeh M, Pritzker M, Delacourt C, Liu SW, Fowler M. Method of the four-electrode electrochemical cell for the characterization of concentrated binary electrolytes: Theory and application. J Phys Chem C. 2017; 121: 4112-4129.

69. Landesfeind J, Gasteiger HA. Temperature and concentration dependence of the ionic transport properties of lithium-ion battery electrolytes. J Electrochem Soc. 2019; 166: A3079-A3097.

70. Nishikawa K, Fukunaka Y, Sakka T, Ogata YH, Selman JR. Measurement of $\mathrm{LiClO}_{4}$ diffusion coefficient in propylene carbonate by moiré pattern. J Electrochem Soc. 2006; 153: A830.

71. Nishida T, Nishikawa K, Fukunaka Y. Diffusivity measurement of LiPF, LiTFSI, LiBF 4 in PC. ECS Trans. 2008; 6: 1-14.

72. Quickenden $\mathrm{TI}$, Jiang X. The diffusion coefficient of copper sulfate in aqueous solution. Electrochim Acta. 1984; 29: 693-700.

73. Uceda D, O'Keefe T, Cole E. Mass-transfer measurements of copper deposition in a fluosilicate electrolyte. J Electrochem Soc. 1990; 137: 1397-1402.

74. Lee SI. The electrochemical reaction characteristics of aluminum rotating disk electrode. Korean Chem Eng Res. 2000; 38: 129.

75. Osman Z, Ghazali MM, Othman L, Isa KM. AC ionic conductivity and DC polarization method of

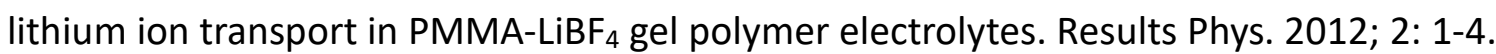

76. Ding MS, Jow TR. Conductivity and viscosity of PC-DEC and PC-EC solutions of LiPF6. J Electrochem Soc. 2003; 150: A620.

77. Karatrantos AV, Ohba T, Cai Q. Diffusion of ions and solvent in propylene carbonate solutions for lithium-ion battery applications. J Mol Liq. 2020; 320: 114351.

78. Allen MP, Tildesley DJ. Computer simulation of liquids. Oxford: Clarendon Press; 1987.

79. Karatrantos A, Composto RJ, Winey KI, Kröger M, Clarke N. Entanglements and dynamics of polymer melts near a SWCNT. Macromolecules. 2012; 45: 7274-7281.

80. Karatrantos $\mathrm{A}$, Cai $\mathrm{Q}$. Effects of pore size and surface charge on $\mathrm{Na}$ ion storage in carbon nanopores. Phys Chem Chem Phys. 2016; 18: 30761-30769.

81. Khan MS, Karatrantos AV, Ohba T, Cai Q. The effect of different organic solvents and anion salts on sodium ion storage in cylindrical carbon nanopores. Phys Chem Chem Phys. 2019; 21: 2272222731.

82. Karatrantos $A$, Khan $S$, Ohba $T$, Cai $Q$. The effect of different organic solvents on sodium ion storage in carbon nanopores. Phys Chem Chem Phys. 2018; 20: 6307-6315.

83. Karatrantos A, Composto RJ, Winey KI, Clarke N. Polymer and spherical nanoparticle diffusion in nanocomposites. J Chem Phys. 2017; 146: 203331.

84. Karatrantos A, Composto RJ, Winey KI, Clarke N. Nanorod diffusion in polymer nanocomposites by molecular dynamics simulations. Macromolecules. 2019; 52: 2513-2520.

85. Moghimikheirabadi A, Mugemana C, Kröger M, Karatrantos AV. Polymer conformations, entanglements and dynamics in ionic nanocomposites: A molecular dynamics study. Polymers. 
2020; 12: 2591.

86. Karatrantos A, Composto RJ, Winey KI, Kröger M, Clarke N. Modeling of entangled polymer diffusion in melts and nanocomposites: A review. Polymers. 2019; 11: 876.

87. Hayamizu K. Temperature dependence of self-diffusion coefficients of ions and solvents in ethylene carbonate, propylene carbonate, and diethyl carbonate single solutions and ethylene carbonate + diethyl carbonate binary solutions of LiPF 6 studied by NMR. J Chem Eng Data. 2012; 57: 2012-2017.

88. Aihara $\mathrm{Y}$, Sugimoto $\mathrm{K}$, Price WS, Hayamizu K. Ionic conduction and self-diffusion near infinitesimal concentration in lithium salt-organic solvent electrolytes. J Chem Phys. 2000; 113: 1981-1991.

89. Islam MS, Fisher CA. Lithium and sodium battery cathode materials: Computational insights into voltage, diffusion and nanostructural properties. Chem Soc Rev. 2014; 43: 185-204.

90. Mo Y, Ong SP, Ceder G. First principles study of the $\mathrm{Li}_{10} \mathrm{GeP}_{2} \mathrm{~S}_{12}$ lithium super ionic conductor material. Chem Mater. 2012; 24: 15-17.

91. Ong SP, Mo Y, Richards WD, Miara L, Lee HS, Ceder G. Phase stability, electrochemical stability and ionic conductivity of the $\mathrm{Li}_{10 \pm 1} \mathrm{MP}_{2} \mathrm{X}_{12}(\mathrm{M}=\mathrm{Ge}, \mathrm{Si}, \mathrm{Sn}, \mathrm{Al}$ or $\mathrm{P}$, and $\mathrm{X}=\mathrm{O}, \mathrm{S}$ or Se) family of superionic conductors. Energy Environ Sci. 2013; 6: 148-156.

92. Car R, Parrinello M. Unified approach for molecular dynamics and density-functional theory. Phys Rev Lett. 1985; 55: 2471-2474.

93. Gibson DA, lonova IV, Carter EA. A comparison of Car-Parrinello and Born-Oppenheimer generalized valence bond molecular dynamics. Chem Phys Lett. 1995; 240: 261-267.

94. Barnett RN, Landman U. Born-Oppenheimer molecular-dynamics simulations of finite systems: Structure and dynamics of $\left(\mathrm{H}_{2} \mathrm{O}\right)_{2}$. Phy Rev B. 1993; 48: 2081-2097.

95. Wentzcovitch RM, Martins J. First principles molecular dynamics of Li: Test of a new algorithm. Solid State Commun. 1991; 78: 831-834.

96. Su CC, He M, Amine R, Chen Z, Amine K. The relationship between the relative solvating power of electrolytes and shuttling effect of lithium polysulfides in lithium-sulfur batteries. Angew Chem Int Ed. 2018; 57: 12033-12036.

97. Hayamizu K, Akiba E. An evaluation method of liquid electrolytes for lithium batteries by the multinuclear pulsed-gradient spin-echo NMR-the diffusing radii of lithium ion and anions in organic solvents. Electrochemistry. 2003; 71: 1052-1054.

98. Kubisiak $P$, Wróbel $P$, Eilmes A. Molecular dynamics investigation of correlations in ion transport in MeTFSI/EMIM-TFSI (Me = Li, Na) electrolytes. J Phys Chem B. 2019; 124: 413-421.

99. Takeuchi M, Kameda Y, Umebayashi Y, Ogawa S, Sonoda T, Ishiguro SI, et al. Ion-ion interactions of $\mathrm{LiPF}_{6}$ and $\mathrm{LiBF}_{4}$ in propylene carbonate solutions. J Mol Liq. 2009; 148: 99-108.

100. Ganesh P, Jiang DE, Kent PR. Accurate static and dynamic properties of liquid electrolytes for Liion batteries from ab initio molecular dynamics. J Phys Chem B. 2011; 115: 3085-3090.

101. Saito Y, Yamamoto H, Nakamura O, Kageyama H, Ishikawa H, Miyoshi T, et al. Determination of ionic self-diffusion coefficients of lithium electrolytes using the pulsed field gradient NMR. J Power Sources. 1999; 81: 772-776.

102. Aihara $Y$, Bando $T$, Nakagawa $H$, Yoshida $H$, Hayamizu $K$, Akiba $E$, et al. The characteristic properties of ions for six lithium salts, including lithium bis-(oxorateborate) dissolved in $\gamma$ butyrolactone. J Electrochem Soc. 2004; 151: A119-A122.

103. Hayamizu K, Aihara Y. Ion and solvent diffusion and ion conduction of PC-DEC and PC-DME 
binary solvent electrolytes of $\mathrm{LiN}\left(\mathrm{SO}_{2} \mathrm{CF}_{3}\right)_{2}$. Electrochim Acta. 2004; 49: 3397-3402.

104. Kondo K, Sano M, Hiwara A, Omi T, Fujita M, Kuwae A, et al. Conductivity and solvation of $\mathrm{Li}^{+}$ ions of $\mathrm{LiPF}_{6}$ in propylene carbonate solutions. J Phys Chem B. 2000; 104: 5040-5044.

105. Hwang S, Kim DH, Shin JH, Jang JE, Ahn KH, Lee C, et al. lonic conduction and solution structure in $\mathrm{LiPF}_{6}$ and $\mathrm{LiBF}_{4}$ propylene carbonate electrolytes. J Phys Chem C. 2018; 122: 19438-19446.

106. Doi K, Chikasako Y, Kawano S. Theoretical study of solvation effect on diffusion coefficient of Li ion in propylene carbonate. Fluid Dyn Mater Process. 2015; 11: 1-26.

107. Self J, Fong KD, Persson KA. Transport in superconcentrated $\mathrm{LiPF}_{6}$ and $\mathrm{LiBF}_{4} /$ propylene carbonate electrolytes. ACS Energy Lett. 2019; 4: 2843-2849.

108. Bedrov D, Piquemal JP, Borodin O, MacKerell Jr AD, Roux B, Schröder C. Molecular dynamics simulations of ionic liquids and electrolytes using polarizable force fields. Chem Rev. 2019; 119: 7940-7995.

109. Richardson PM, Voice AM, Ward IM. Pulsed-field gradient NMR self diffusion and ionic conductivity measurements for liquid electrolytes containing $\mathrm{LiBF}_{4}$ and propylene carbonate. Electrochim Acta. 2014; 130: 606-618.

110. Berhaut CL, Porion P, Timperman L, Schmidt G, Lemordant D, Anouti M. LiTDI as electrolyte salt for Li-ion batteries: Transport properties in EC/DMC. Electrochim Acta. 2015; 180: 778-787.

111. Huckel E, Debye P. Zur theorie der elektrolyte. i. gefrierpunktserniedrigung und verwandte erscheinungen. Phys Z. 1923; 185: 305.

112. Fuoss RM. Conductance of dilute solutions of 1-1 electrolytes ${ }^{1}$. J Am Chem Soc. 1959; 81: 26592662.

113. Hou T, Monroe CW. Composition-dependent thermodynamic and mass-transport characterization of lithium hexafluorophosphate in propylene carbonate. Electrochim Acta. 2020; 332: 135085.

114.Ding MS, Xu K, Zhang SS, Amine K, Henriksen GL, Jow TR. Change of conductivity with salt content, solvent composition, and temperature for electrolytes of $\mathrm{LiPF}_{6}$ in ethylene carbonateethyl methyl carbonate. J Electrochem Soc. 2001; 148: A1196.

115. Capiglia C, Saito Y, Kageyama H, Mustarelli P, Iwamoto T, Tabuchi T, et al. 7Li and 19F diffusion coefficients and thermal properties of non-aqueous electrolyte solutions for rechargeable lithium batteries. J Power Sources. 1999; 81: 859-862.

116. Aihara $\mathrm{Y}$, Bando $T$, Nakagawa $H$, Yoshida $H$, Hayamizu K, Akiba $E$, et al. Ion transport properties of six lithium salts dissolved in $\gamma$-butyrolactone studied by self-diffusion and ionic conductivity measurements. J Electrochem Soc. 2003; 151: A119.

117. Clericuzio M, Parker Jr WO, Soprani M, Andrei M. lonic diffusivity and conductivity of plasticized polymer electrolytes: PMFG-NMR and complex impedance studies. Solid State Ion. 1995; 82: 179-192.

118. Cresce AV, Russell SM, Borodin O, Allen JA, Schroeder MA, Dai M, et al. Solvation behavior of carbonate-based electrolytes in sodium ion batteries. Phys Chem Chem Phys. 2017; 19: 574-586.

119. Neuhaus J, Bellaire D, Kohns M, von Harbou E, Hasse H. Self-diffusion coefficients in solutions of lithium bis (fluorosulfonyl) imide with dimethyl carbonate and ethylene carbonate. Chem Ing Tech. 2019; 91: 1633-1639.

120.Porion P, Dougassa YR, Tessier C, El Ouatani L, Jacquemin J, Anouti M. Comparative study on transport properties for LiFAP and LiPF 6 in alkyl-carbonates as electrolytes through conductivity, viscosity and NMR self-diffusion measurements. Electrochim Acta. 2013; 114: 95-104. 
121.Garrido L, Mejía A, García N, Tiemblo P, Guzmán J. Ion diffusion coefficients model and molar conductivities of ionic salts in aprotic solvents. J Phys Chem B. 2015; 119: 3097-3103.

122. Ringsby AJ, Fong KD, Self J, Bergstrom HK, McCloskey BD, Persson KA. Transport phenomena in low temperature lithium-ion battery electrolytes. J Electrochem Soc. 2021; 168: 080501.

123. Bizeray AM, Howey DA, Monroe CW. Resolving a discrepancy in diffusion potentials, with a case study for Li-ion batteries. J Electrochem Soc. 2016; 163: E223.

124. Kim SU, Srinivasan V. A method for estimating transport properties of concentrated electrolytes from self-diffusion data. J Electrochem Soc. 2016; 163: A2977.

125. Krishna R, Van Baten JM. The darken relation for multicomponent diffusion in liquid mixtures of linear alkanes: An investigation using molecular dynamics (MD) simulations. Ind Eng Chem Res. 2005; 44: 6939-6947.

126. Dahbi M, Ghamouss F, Tran-Van F, Lemordant D, Anouti M. Comparative study of EC/DMC LiTFSI and LiPF 6 electrolytes for electrochemical storage. J Power Sources. 2011; 196: 9743-9750.

127. Yim CH, Tam J, Soboleski H, Abu-Lebdeh Y. On the correlation between free volume, phase diagram and ionic conductivity of aqueous and non-aqueous lithium battery electrolyte solutions over a wide concentration range. J Electrochem Soc. 2017; 164: A1002-A1011.

128. Lee SI, Jung UH, Kim YS, Kim MH, Ahn DJ, Chun HS. A study of electrochemical kinetics of lithium ion in organic electrolytes. Korean J Chem Eng. 2002; 19: 638-644.

129. Karatrantos A, Koutsawa Y, Dubois P, Clarke N, Kröger M. Miscibility and nanoparticle diffusion in ionic nanocomposites. Polymers. 2018; 10: 1010.

130. Han S. Structure and dynamics in the lithium solvation shell of nonaqueous electrolytes. Sci Rep. 2019; 9: 5555.

131. Ravikumar B, Mynam M, Rai B. Effect of salt concentration on properties of lithium ion battery electrolytes: A molecular dynamics study. J Phys Chem C. 2018; 122: 8173-8181.

132.Liyana-Arachchi TP, Haskins JB, Burke CM, Diederichsen KM, McCloskey BD, Lawson JW. Polarizable molecular dynamics and experiments of 1, 2-dimethoxyethane electrolytes with lithium and sodium salts: Structure and transport properties. J Phys Chem B. 2018; 122: 85488559.

133.Pham TA, Kweon KE, Samanta A, Lordi V, Pask JE. Solvation and dynamics of sodium and potassium in ethylene carbonate from ab initio molecular dynamics simulations. J Phys Chem C. 2017; 121: 21913-21920.

134. Soetens JC, Millot C, Maigret B. Molecular dynamics simulation of $\mathrm{Li}^{+} \mathrm{BF}_{4}{ }^{-}$in ethylene carbonate, propylene carbonate, and dimethyl carbonate solvents. J Phys Chem A. 1998; 102: 1055-1061.

135. Hanke F, Modrow N, Akkermans RL, Korotkin I, Mocanu FC, Neufeld VA, et al. Multi-scale electrolyte transport simulations for lithium ion batteries. J Electrochem Soc. 2019; 167: 013522.

136. Mynam M, Ravikumar B, Rai B. Molecular dynamics study of propylene carbonate based concentrated electrolyte solutions for lithium ion batteries. J Mol Liq. 2019; 278: 97-104.

137. Tenney CM, Cygan RT. Analysis of molecular clusters in simulations of lithium-ion battery electrolytes. J Phys Chem C. 2013; 117: 24673-24684.

138. Borodin O, Smith GD. LiTFSI structure and transport in ethylene carbonate from molecular dynamics simulations. J Phys Chem B. 2006; 110: 4971-4977.

139. Han S. A salient effect of density on the dynamics of nonaqueous electrolytes. Sci Rep. 2017; 7: 46718.

140.Bhatt MD, Cho M, Cho K. Density functional theory calculations and ab initio molecular 
dynamics simulations for diffusion of $\mathrm{Li}^{+}$within liquid ethylene carbonate. Model Simul Mat Sci Eng. 2012; 20: 065004.

141. Ong MT, Verners O, Draeger EW, Van Duin AC, Lordi V, Pask JE. Lithium ion solvation and diffusion in bulk organic electrolytes from first-principles and classical reactive molecular dynamics. J Phys Chem B. 2015; 119: 1535-1545.

142. Chaudhari MI, Nair JR, Pratt LR, Soto FA, Balbuena PB, Rempe SB. Scaling atomic partial charges of carbonate solvents for lithium ion solvation and diffusion. J Chem Theory Comput. 2016; 12: 5709-5718.

143.Pean C, Daffos B, Rotenberg B, Levitz P, Haefele M, Taberna PL, et al. Confinement, desolvation, and electrosorption effects on the diffusion of ions in nanoporous carbon electrodes. J Am Chem Soc. 2015; 137: 12627-12632.

144.Smart MC, Ratnakumar BV, Surampudi S. Electrolytes for low-temperature lithium batteries based on ternary mixtures of aliphatic carbonates. J Electrochem Soc. 1999; 146: 486.

145. Postupna OO, Kolesnik YV, Kalugin ON, Prezhdo OV. Microscopic structure and dynamics of LiBF 4 solutions in cyclic and linear carbonates. J Phys Chem B. 2011; 115: 14563-14571.

146. Borodin O, Smith GD. Quantum chemistry and molecular dynamics simulation study of dimethyl carbonate: Ethylene carbonate electrolytes doped with LiPF6. J Phys Chem B. 2009; 113: 17631776.

147.Gao T, Lu W. Mechanism and effect of thermal degradation on electrolyte ionic diffusivity in Liion batteries: A molecular dynamics study. Electrochim Acta. 2019; 323: 134791.

148. Kumar G, Kartha TR, Mallik BS. Novelty of lithium salt solution in sulfone and dimethyl carbonate-based electrolytes for lithium-ion batteries: A classical molecular dynamics simulation study of optimal ion diffusion. J Phys Chem C. 2018; 122: 26315-26325.

149.Shim Y. Computer simulation study of the solvation of lithium ions in ternary mixed carbonate electrolytes: Free energetics, dynamics, and ion transport. Phys Chem Chem Phys. 2018; 20: 28649-28657.

150. Kumar N, Seminario JM. Lithium-ion model behavior in an ethylene carbonate electrolyte using molecular dynamics. J Phys Chem C. 2016; 120: 16322-16332.

151.Salanne M. Simulations of room temperature ionic liquids: From polarizable to coarse-grained force fields. Phys Chem Chem Phys. 2015; 17: 14270-14279.

152. Hayashi K, Nemoto Y, Tobishima SI, Yamaki JI. Electrolyte for high voltage $\mathrm{Li} / \mathrm{LiMn}{ }_{1.9} \mathrm{CO}_{0.1} \mathrm{O}_{4}$ cells. J Power Sources. 1997; 68: 316-319.

153.Saunier J, Gorecki W, Alloin F, Sanchez JY. NMR study of cation, anion, and solvent mobilities in macroporous poly (vinylidene fluoride). J Phys Chem B. 2005; 109: 2487-2492.

154.Borodin O, Smith GD. Development of many-body polarizable force fields for Li-battery applications: 2. LiTFSI-doped oligoether, polyether, and carbonate-based electrolytes. J Phys Chem B. 2006; 110: 6293-6299.

155. Brouillette D, Perron G, Desnoyers JE. Apparent molar volume, heat capacity, and conductance of lithium bis (trifluoromethylsulfone) imide in glymes and other aprotic solvents. J Solution Chem. 1998; 27: 151-182.

156. Kirshnamoorthy AN, Oldiges K, Winter M, Heuer A, Cekic-Laskovic I, Holm C, et al. Electrolyte solvents for high voltage lithium ion batteries: Ion correlation and specific anion effects in adiponitrile. Phys Chem Chem Phys. 2018; 20: 25701-25715.

157. Han KS, Rajput NN, Wei X, Wang W, Hu JZ, Persson KA, et al. Diffusional motion of redox centers 
in carbonate electrolytes.J Chem Phys. 2014; 141: 104509.

158.Zhan C, Liu W, Hu M, Liang Q, Yu X, Shen Y, et al. High-performance sodium-ion hybrid capacitors based on an interlayer-expanded $\mathrm{MoS}_{2} / \mathrm{rGO}$ composite: Surpassing the performance of lithiumion capacitors in a uniform system. NPG Asia Mater. 2018; 10: 775-787.

159. Coles SW, Smith AM, Fedorov MV, Hausen F, Perkin S. Interfacial structure and structural forces in mixtures of ionic liquid with a polar solvent. Faraday Discuss. 2017; 206: 427-442.

160. Park C, Kanduč M, Chudoba R, Ronneburg A, Risse S, Ballauff M, et al. Molecular simulations of electrolyte structure and dynamics in lithium-sulfur battery solvents. J Power Sources. 2018; 373: 70-78.

161. Osella S, Minoia A, Quarti C, Cornil J, Lazzaroni R, Goffin AL, et al. Modelling coupled ion motion in electrolyte solutions for lithium-sulfur batteries. Batteries Supercaps. 2019; 2: 473-481.

162. Åvall G, Mindemark J, Brandell D, Johansson P. Sodium-ion battery electrolytes: Modeling and simulations. Adv Energy Mater. 2018; 8: 1703036.

163. Monti D, Jónsson E, Boschin A, Palacín MR, Ponrouch A, Johansson P. Toward standard electrolytes for sodium-ion batteries: Physical properties, ion solvation and ion-pairing in alkyl carbonate solvents. Phys Chem Chem Phys. 2020; 22: 22768-22777.

164. Matsuda Y, Nakashima H, Morita M, Takasu Y. Behavior of some ions in mixed organic electrolytes of high energy density batteries. J Electrochem Soc. 1981; 128: 2552.

165.Jónsson E, Johansson P. Modern battery electrolytes: Ion-ion interactions in $\mathrm{Li}^{+} / \mathrm{Na}^{+}$conductors from DFT calculations. Phys Chem Chem Phys. 2012; 14: 10774-10779.

166. Okoshi M, Yamada Y, Yamada A, Nakai H. Theoretical analysis on de-solvation of lithium, sodium, and magnesium cations to organic electrolyte solvents. J Electrochem Soc. 2013; 160: A2160A2165.

167. Vaalma C, Buchholz D, Passerini S. Non-aqueous potassium-ion batteries: A review. Curr Opin Electrochem. 2018; 9: 41-48.

168. Seki S, Hayamizu K, Tsuzuki S, Takahashi K, Ishino Y, Kato M, et al. Density, viscosity, ionic conductivity, and self-diffusion coefficient of organic liquid electrolytes: Part I. Propylene carbonate $+\mathrm{Li}, \mathrm{Na}, \mathrm{Mg}$ and Ca cation salts. J Electrochem Soc. 2018; 165: A542-A546.

169.Landesfeind J, Hosaka T, Graf M, Kubota K, Komaba S, Gasteiger HA. Comparison of ionic transport properties of non-aqueous lithium and sodium hexafluorophosphate electrolytes. J Electrochem Soc. 2021;168: 040538.

170. Kuratani K, Uemura N, Senoh H, Takeshita HT, Kiyobayashi T. Conductivity, viscosity and density of $\mathrm{MClO} 4(\mathrm{M}=\mathrm{Li}$ and $\mathrm{Na}$ ) dissolved in propylene carbonate and $\mathrm{\gamma}$-butyrolactone at high concentrations. J Power Sources. 2013; 223: 175-182.

171.Chen HP, Fergus JW, Jang BZ. The effect of ethylene carbonate and salt concentration on the conductivity of propylene carbonate | lithium perchlorate electrolytes. J Electrochem Soc. 2000; 147: 399.

172. Morales D, Chagas LG, Paterno D, Greenbaum S, Passerini S, Suarez S. Transport studies of NaPF 6 carbonate solvents-based sodium ion electrolytes. Electrochim Acta. 2021; 377: 138062.

173. Hosaka T, Kubota K, Kojima H, Komaba S. Highly concentrated electrolyte solutions for $4 \mathrm{~V}$ class potassium-ion batteries. Chem Commun. 2018; 54: 8387-8390.

174. Okoshi M, Chou CP, Nakai $\mathrm{H}$. Theoretical analysis of carrier ion diffusion in superconcentrated electrolyte solutions for sodium-ion batteries. J Phys Chem B. 2018; 122: 2600-2609.

175.Bedrov D, Borodin O, Smith GD, Trouw F, Mayne C. Simulation and QENS studies of molecular 
dynamics in aqueous solutions of 1, 2-dimethoxyethane. J Phys Chem B. 2000; 104: 5151-5154. 176.Xu K, von Wald Cresce A. $\mathrm{Li}^{+}$-solvation/desolvation dictates interphasial processes on graphitic anode in Li ion cells. J Mater Res. 2012; 27: 2327-23241.

177. Ravikumar B, Kumari S, Mynam M, Rai B. Effect of temperature and salt concentration on the properties of electrolyte for sodium-ion batteries. In: Proceedings of the 7th International Conference on Advances in Energy Research. Singapore: Springer; 2021. pp.1071-1081.

178. Kamath G, Cutler RW, Deshmukh SA, Shakourian-Fard M, Parrish R, Huether J, et al. In silico based rank-order determination and experiments on nonaqueous electrolytes for sodium ion battery applications. J Phys Chem C. 2014; 118: 13406-13416.

179. Drews J, Danner T, Jankowski P, Vegge T, Lastra JM, Liu R, et al. Modeling of ion agglomeration in magnesium electrolytes and its impacts on battery performance. ChemSusChem. 2020; 13: 3599-3604.

180.Li Y, Guan S, Huo H, Ma Y, Gao Y, Zuo P, et al. A review of magnesium aluminum chloride complex electrolytes for Mg batteries. Adv Funct Mater. 2021; 31: 2100650.

181. Araujo RB, Thangavel V, Johansson P. Toward novel calcium battery electrolytes by efficient computational screening. Energy Stor Mater. 2021; 39: 89-95.

182.Xu C, Li B, Du H, Kang F. Energetic zinc ion chemistry: The rechargeable zinc ion battery. Angew Chem. 2012; 51: 933-935.

183. Das SK, Mahapatra S, Lahan H. Aluminium-ion batteries: Developments and challenges. J Mater Chem A. 2017; 5: 6347-6367.

184. Hu Y, Sun D, Luo B, Wang L. Recent progress and future trends of aluminum batteries. Energy Technol. 2019; 7: 86-106.

185.Zhang K, Kirlikovali KO, Suh JM, Choi JW, Jang HW, Varma RS, et al. Recent advances in rechargeable aluminum-ion batteries and considerations for their future progress. ACS Appl Energy Mater. 2020; 3: 6019-6035.

186. Aurbach D, Weissman I, Gofer Y, Levi E. Nonaqueous magnesium electrochemistry and its application in secondary batteries. Chem Rec. 2003; 3: 61-73.

187.Gao T, Noked M, Pearse AJ, Gillette E, Fan X, Zhu Y, et al. Enhancing the reversibility of Mg/S battery chemistry through $\mathrm{Li}^{+}$mediation. J Am Chem Soc. 2015; 137: 12388-12393.

188. Lipson AL, Pan B, Lapidus SH, Liao C, Vaughey JT, Ingram BJ. Rechargeable Ca-ion batteries: A new energy storage system. Chem Mater. 2015; 27: 8442-8447.

189.Shakourian-Fard M, Kamath G, Sankaranarayanan SK. Electronic structure insights into the solvation of magnesium ions with cyclic and acyclic carbonates. ChemPhysChem. 2015; 16: 3607-3617.

190.Shakourian-Fard M, Kamath G, Sankaranarayanan SK. Evaluating the free energies of solvation and electronic structures of lithium-ion battery electrolytes. ChemPhysChem. 2016; 17: 29162930.

191. Rajput NN, Qu X, Sa N, Burrell AK, Persson KA. The coupling between stability and ion pair formation in magnesium electrolytes from first-principles quantum mechanics and classical molecular dynamics. J Am Chem Soc. 2015; 137: 3411-3420.

192.Samuel D, Steinhauser C, Smith JG, Kaufman A, Radin MD, et al. Ion pairing and diffusion in magnesium electrolytes based on magnesium borohydride. ACS Appl Mater Interfaces. 2017; 9 : 43755-43766.

193.Li XY, Nie J. Density functional theory study on metal bis (trifluoromethylsulfonyl) imides: 
Electronic structures, energies, catalysis, and predictions. J Phys Chem A. 2003; 107: 6007-6013. 194.Lapidus SH, Rajput NN, Qu X, Chapman KW, Persson KA, Chupas PJ. Solvation structure and energetics of electrolytes for multivalent energy storage. Phys Chem Chem Phys. 2014; 16: 21941-21945.

195.Shannon RD. Revised effective ionic radii and systematic studies of interatomic distances in halides and chalcogenides. Acta Crystallogr A. 1976; 32: 751-767.

196. Blanc LE, Kundu D, Nazzar LF. Scientific challenges for the implementation of Zn-lon batteries. Joule. 2020; 4: 4: 771-799.

197. Han SD, Rajput NN, Qu X, Pan B, He M, Ferrandon MS, et al. Origin of electrochemical, structural, and transport properties in nonaqueous zinc electrolytes. ACS Appl Mater Interfaces. 2016; 8: 3021-3031.

198.Sullivan JM, Hanson DC, Keller R. Diffusion coefficients in propylene carbonate, dimethyl formamide, acetonitrile, and methyl formate. J Electrochem Soc. 1970; 117: 779.

199. Naveed A, Yang H, Shao Y, Yang J, Yanna N, Liu J, et al. A highly reversible Zn anode with intrinsically safe organic electrolyte for long-cycle-life batteries. Adv Mater. 2019; 31: 1900668.

200.Logan ER, Tonita EM, Gering KL, Li J, Ma X, Beaulieu LY, et al. A study of the physical properties of Li-ion battery electrolytes containing esters. J Electrochem Soc. 2018; 165: A21.

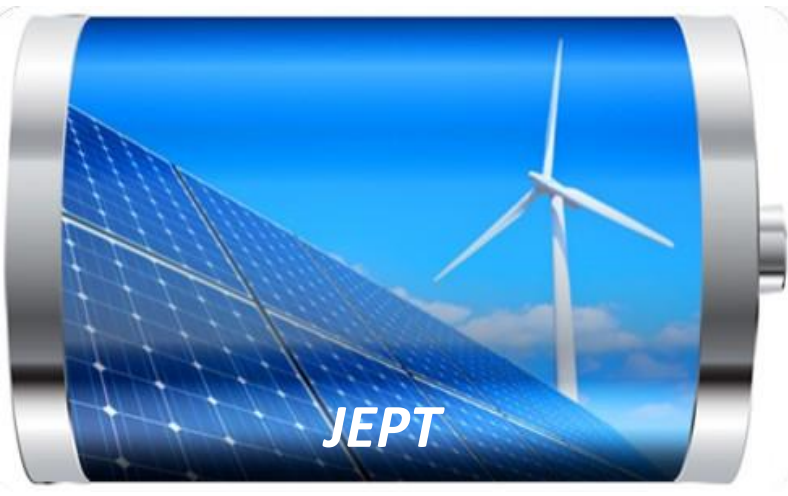

Enjoy JEPT by:

1. Submitting a manuscript

2. Joining in volunteer reviewer bank

3. Joining Editorial Board

4. Guest editing a special issue

For more details, please visit http://www.lidsen.com/journal/jept 